Canadian

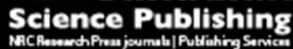

Canadian Geotechnical Journal Revue canadienne de géotechnique

\title{
Application of a portable free-fall penetrometer for the geotechnical investigation of the Arctic nearshore zone
}

\begin{tabular}{|r|l|}
\hline Journal: & Canadian Geotechnical Journal \\
\hline Manuscript ID & cgj-2016-0087.R1 \\
\hline Manuscript Type: & Article \\
\hline Complete List of Authors: & $\begin{array}{l}\text { Stark, Nina; Virginia Tech, Civil and Environmental Engineering } \\
\text { Radosavljević, Boris; Alfred-Wegener-Institut fur Polar und } \\
\text { Meeresforschung Forschungsstelle Potsdam; Universitat Potsdam, Institute } \\
\text { of Earth- and Environmental Science } \\
\text { Quinn, Brandon; Virginia Polytechnic Institute and State University, Civil } \\
\text { and Environmental Engineering } \\
\text { Lantuit, Hugues; Alfred-Wegener-Institut fur Polar und Meeresforschung } \\
\text { Forschungsstelle Potsdam; Universitat Potsdam, Institute of Earth- and } \\
\text { Environmental Science }\end{array}$ \\
\hline Keyword: & $\begin{array}{l}\text { free fall penetrometer, sediment stratification, sediment strength, coastal } \\
\text { processes, Herschel Island }\end{array}$ \\
\hline &
\end{tabular}




\section{Application of a portable free-fall penetrometer for the geotechnical investigation of the Arctic nearshore zone}

Nina Stark ${ }^{1 *}$, Boris Radosavljevic ${ }^{2,3}$, Brandon Quinn $^{1}$, Hugues Lantuit ${ }^{2,3}$

\footnotetext{
${ }^{1}$ Virginia Tech, Dept. of Civil and Environmental Engineering, 200 Patton Hall, Blacksburg, VA 24060, US, phone: +1-540-922-3951, email: ninas@vt.edu,

${ }^{2}$ Alfred Wegener Institute, Helmholtz Centre for Polar and Marine Research, Research Unit Potsdam, Potsdam, Germany

${ }^{3}$ Institute of Earth- and Environmental Science, University of Potsdam, Potsdam, Germany

*corresponding author
} 


\begin{abstract}
The Arctic is currently undergoing rapid changes with regard to sea ice extent, permafrost thaw and coastal erosion. In addition to hydrodynamic processes, the sediments in the Arctic nearshore zone are affected by freeze-thaw cycles, as well as an increase of abundant suspended sediment introduced by permafrost-induced mass movements, such as retrogressive thaw slumps, and increased river discharge. During the YUKON14 expedition to Herschel Island, Yukon, in-situ geotechnical testing of nearshore zone sediments was conducted using a portable free fall penetrometer. Approximately 200 sites were tested, and four different geotechnical signatures identified and grouped. Most locations were characterized by a soft sediment top layer that exhibited a noticeably lower sediment strength than the underlying sediment. In some cases, multiple layers of different sediment strength were detected in the upper meter of the seabed surface. The results were correlated to existing sediment grain size records and backscatter information from a phase measuring bathymetric sonar. Strong spatial variations in sediment type and stiffness were observed, as well as in abundance and thickness of a top layer of very soft and loose sediment. The geotechnical signatures were correlated to site-specific hydrodynamic conditions, morphology, and vicinity to thaw slumps.
\end{abstract}

Keywords:

Herschel Island, free fall penetrometer, sediment stratification, sediment strength, coastal processes 


\section{Introduction}

The Arctic is currently undergoing rapid changes with regard to sea ice extent and permafrost in response to climate change (Gardner et al. 2011; Vaughan et al. 2013). Thawing of permafrost directly impacts slope stability, while the retreat of sea ice increases the chance for waves to hit the coast, facilitating coastal erosion. Rapid advances of coastal erosion have been documented in several Arctic areas resulting in substantial losses of land, infrastructure and heritage sites, but also to the release of carbon stored in the frozen soil (Lantuit and Pollard 2008; Jones et al. 2009; Radosavljevic et al. 2015). Yet, the prediction of coastal erosion in the Arctic is difficult, because of the spatial and temporal variability and the very diverse nature of processes involved (Lantuit et al. 2012; Cruden and Martin 2013; Fritz et al. 2015; Ping et al. 2015). While the movement of the shorelines or the occurrence of thermokarst in the subaerial part of the coastal profile have been the subject of numerous investigations (Lantuit and Pollard, 2005; Günther et al. 2013; Radosavljevic et al. 2015), little is known about the link to nearshore processes, and in particular, to the mechanical properties of sediment at shallow depths. This mostly results from the logistical challenges associated with coastal surveying and deploying instruments in the Arctic.

The nearshore zone might in fact be subject to a combination of thermal and mechanical processes similar to the ones affecting permafrost on land, but is also subject to forcing from hydrodynamics and to the presence of sea ice (as bottom fast ice or fast ice) (Dallimore et al. 1996). Processes related to permafrost on land are classified as thermal and mechanical processes (Marsh and Neumann 2001). Soil mechanical processes are directly affected by thermal processes, as well as sediment dynamics (Jumikis 1977; Stark and Kopf 2011). Permafrost is warming in the Arctic, reflected in a decrease in areal extent and a deepening of the active layer, synonymous with thawing of permafrost soils (Romanovsky et al. 2010; Overpeck et al. 1997; Lawrence et al. 2008). The active layer overlying the permafrost 
undergoes annual freeze- and thaw cycles. Such freeze-thaw processes directly impact the geotechnical characteristics of the soil, as demonstrated by researchers such as Qi et al. (2008) and Aubert and Gasc-Barbier (2012). Typically, sediments densify over freeze and thaw processes resulting from desiccation and rearrangement of the dried soil. However, if sediments are wet or saturated, sediment weakening can follow the widening of pore space during freezing, and refilling of widened pore space with water during thawing. Researchers such as Buteau et al. (2005) also found a strong variability of soil strength in the active permafrost layer that defines the zone in which the thaw front varies over time.

Surficial nearshore- and coastal sediments are also exposed to marine processes during the open-water season, and possibly scour by ice when it is present. Unless frozen, sediments can be mobilized through waves and currents (Burn and Lewkowicz 1990; Murton 2001). In addition to sediments supplied to the nearshore by coastal erosion, retrogressive thaw slumps, thermokarst features associated with ice-rich permafrost may deliver additional sediment to the nearshore through denudation of the backshore. These sediments undergo transport and deposition, and may freeze at a new locations again over the next winter season (Reimnitz et al. 1987). Stevens et al. $(2009 ; 2010)$ demonstrated that the combination of fast ice presence could lead to the freezing of substantial parts of the nearshore area and ultimately to the presence of permafrost at relatively shallow depths.

This leads to a number of still unsolved research questions: How do freeze-thaw cycles impact soil mechanical behavior and the erodibility of sediment? How do these properties get shaped or modified by wave forcing? And how does the supply of sediment from the shore (or from longshore drift) contribute to alter these dynamics? The small number of studies devoted to the study of the mechanical properties of nearshore sediments in the Arctic has so far prevented the research community to answer these questions over wide areas. 
During the YUKON14 expedition to Herschel Island $\left(69^{\circ} 36^{\prime} \mathrm{N} 139^{\circ} 04^{\prime} \mathrm{W}\right.$, Fig. 1) in the Canadian Southern Beaufort Sea in July and August 2014, in-situ geotechnical surveying was attempted in the Arctic nearshore zone using a portable free-fall penetrometer (Stark et al. 2015a). Herschel Island was chosen as the focus of the investigations, because of the extensive research related to Arctic coastal erosion performed over the last decades, and multiple visits by interdisciplinary and international research teams (Kokelj et al. 2002; Lantuit and Pollard 2005, 2008; Burn and Zhang 2009). It has a surface area of approximately $120 \mathrm{~km}^{2}$, and the dominant coastal morphology in this study are ice-rich bluffs (25-35 $\mathrm{m}$ in height) fronted by a narrow beach (Harper 1990). The island consists predominantly of silty diamicton, apart from aggradational sandy spits and alluvial fans. Ground ice underlies most of the island, and is exposed close to the coast in some of the world's largest documented retrogressive thaw slumps (Pollard 1990; Obu et al. 2015; Lantuit and Pollard 2005). Lantuit and Pollard (2008) estimated that 1,783,700 $\mathrm{m}^{2}$ were affected by the presence of retrogressive thaw slumps on the island in the year 2000, with as many as 164 slumps of which $46 \%$ are currently active. Coastal erosion rates are generally between 0.5 to $1.0 \mathrm{~m} / \mathrm{yr}$, however erosion rates in excess of $2 \mathrm{~m} / \mathrm{yr}$ were also documented (Lantuit and Pollard 2008; Radosavljevic et al. 2015).)

In this article, the YUKON14 results obtained from the portable free fall penetrometer will be presented and correlated to sediment samples and multi beam echo sounder backscatter intensity. The following research objectives will be addressed: (i) assessment of the performance of a portable free fall penetrometer for the investigation of sediment characteristics and transport processes in Arctic coastal environments, (ii) investigation of geotechnical characteristics and stratification in the uppermost meter of the seabed surface, (iii) correlation of geotechnical signatures to geological and morphological conditions. The 
results represent one part of a larger research effort aiming to understand sediment erosion and deposition processes in the Arctic nearshore zone within an interdisciplinary context.

\section{Methods}

The portable free fall penetrometer BlueDrop (Fig. 2) was designed for the in-situ geotechnical characterization of subaqueous areas of difficult access, and the investigation of subaqueous sediment remobilization and deposition processes (Stark et al. 2014). The design followed the concept of the portable free fall penetrometer Nimrod, one of the first probes successfully deployed in energetic coastal areas for the investigation of highly active sediment dynamics (Stark and Kopf 2011; Stark et al. 2011a). The BlueDrop was chosen for the following reasons: i) Soft, poorly consolidated sediments were expected, and the investigation of the uppermost seabed surface was crucial to derive information regarding ongoing or recent sediment erosion and deposition processes. A heavy and/or frame-based penetrometer would have lacked the sensibility for soft sediments and may have disturbed the sediment surface during the testing. ii) Deployments in the nearshore zone and the direct vicinity of the retrogressive thaw slumps were attempted. Thus, shallow water depths and shoaling waves were expected. The only vessel available to operate in these conditions was a mid-sized Zodiac inflatable boat. A capstan or mobile winch can be installed on such vessels, but was not available during the survey. Therefore, the penetrometer was hand-deployed. Furthermore, a straight free fall and penetration into the soil was desired. In environments of energetic waves, this results in the need for a penetrometer that is free and rapidly "falling" through the water column and approximately fluid dynamically shaped (Stark et al. 2014). The BlueDrop is designed specifically for such environments.

The probe has five on-board microelectromechanical systems (MEMS) accelerometers measuring a range of up to $\pm 250 \mathrm{~g}$ (with $g$ being gravitational acceleration), with an accuracy 
of up to $\pm 1.56 \times 10^{-5} \mathrm{~g}$. A three dimensional MEMS accelerometer $( \pm 55 \mathrm{~g}$ ) determines inclination of the probe. A pressure transducer is located behind the tip (similar to the $u_{2}$ position in standard cone penetration testing). It can measure up to $2 \mathrm{MPa}$ with an accuracy of $\pm 4.67 \times 10^{-4} \mathrm{kPa}$. The pressure was used to estimate water depth from the hydrostatic pressure measured just before impact into the seabed, and to investigate pore pressure. Pore pressure dissipation was tested at only four locations in Pauline Cove (Fig. 1). The results were presented by Stark et al. (2015b). The probe has a length of $\sim 63 \mathrm{~cm}$, and a mass of $\sim 7.8$ $\mathrm{kg}$. The aluminum body can withstand the pressure at water depths of up to $200 \mathrm{~m}$, and the penetrometer tips are manufactured of massive steel. A conical and a hemi-elliptical tip geometry are available. The hemi-elliptical tip was used here (Fig. 2) to increase the sensitivity to soft sediments, decrease drag, and improve the free-fall performance. The deployment sequence was as follows: i) vertical positioning with tip in water (probe is hanging over the reeling); ii) free-fall through the water column (loose rope); iii) impact and penetration into sediment; iv) halt at maximum penetration depth when kinetic energy is depleted; v) recovery with rope. One full deployment sequence in water depths of $<50 \mathrm{~m}$ takes less than one minute if the probe is directly recovered after reaching the halt (Fig. 3).

The probe records continuously at $2 \mathrm{kHz}$ from switch-on to switch-off. Deployments are identified based on time records of the measured deceleration and pressure profiles (Fig. 3). Free-fall through the water column is indicated by rapid downward acceleration of the probe, reaching of an approximate of terminal velocity, and an increase in hydrostatic pressure. True terminal velocity would be reached if (i) the water depth exceeded $\sim 5 \mathrm{~m}$, (ii) no rope were attached, and (iii) no changes in hydrodynamic conditions (currents, waves) occurred. In practice, the probe accelerates following release until terminal velocity is reached, including consideration of probe buoyancy, drag, and rope drag. Then, the probe will experience a continuous slight deceleration in response to the increase of rope drag with the increase of 
rope length. The presence of currents and wave turbulence requires the penetrometer's fins to stir against these flows, and may exhaust more of the kinetic energy. Thus, changes in impact velocity are expected with changes in water depth and hydrodynamic conditions. Impact and penetration into the soil is reflected in a distinct deceleration of the probe that results from the sediment strength, soil buoyancy, and an increase of friction and drag.

The data processing followed the approach introduced by Stark et al. (2011a, 2012b), based on earlier work by Dayal and Allen (1975) and Stoll et al. (2007). The penetrometer is gravity driven. This is opposed by fluid drag on the probe and on the rope during free fall through the water column, and sediment resistance in addition to rope drag upon impact and penetration into the seabed. No further resistance was provided due to the fact that the rope was truly free during deployment. Sediment resistance refers here to soil shearing resistance and soil buoyancy (Scott 1970; Aubeny and Shi 2007), but also an increased drag - regarding the penetrometer body, not rope - (compared to during free fall in fluid) may be considered a contribution to the sediment resistance force. The increase of rope drag over the length of sediment penetration is negligible with regard to the resistance of the sediment, due to the limited penetration depth $(\lesssim 1 \mathrm{~m})$. Skin friction drag is assumed to be negligible for the following reasons: (i) The impact of skin friction decreases with increasing moisture content of the soil (Potyondy 1961). (ii) Although DeJong et al. (2001) documented that metal roughness can have a significant impact on the tip resistance and sleeve friction measured by a penetrometer, in our case, the impact can be considered negligible, because the direct contact of soil along the penetrometer is limited to an approximately $7 \mathrm{~cm}$ long cylindrical section, beyond which the probe diameter decreases toward its tail (Jeanjean et al. 2012). (iii) No significant wear of the penetrometer surface metal was observed during this third survey campaign after manufacturing of the penetrometer (Peuchen 2014). Form drag is expected to increase with the increase of the muddy soil's viscosity compared to the drag experienced 
during free-fall through the water column. From research of shapes in aerospace applications it is known that drag is reduced by about $25-50 \%$ when using a conical nose compared to a blunt, flat face nose. Drag is further reduced to $<5 \%$ using a parabolic nose. From research in the field of torpedo design, relationships between the length of a hemi-elliptic/parabola nose cylindrical center - tail and fins can be developed to minimize drag further (Brooks and Lang 1958). The BlueDrop was designed to realize these optimizations and reduce drag as much as possible. Thus, it may be argued that the increase of form drag plays a minor role for this probe, particularly with the use of the hemi-elliptic nose. Soil buoyancy accounts for the higher density of the sediment compared to water, and the work required to lift the sediment displaced by the penetrometer (Aubeny and Shi 2007; White et al. 2010). To determine the soil buoyancy, the in-situ unit weight of the sediment would be needed (Aubeny and Shi 2007). Considering the field conditions in the Arctic, it is difficult to obtain undisturbed sediment samples. Therefore, the following brief analysis was conducted to assess the potential impact of soil buoyancy. In the case of sandy sediments, penetration depths $\leq 20$ $\mathrm{cm}$ would be expected, even if loose, poorly consolidated sand layers are abundant. Using a submerged unit weight of $\gamma^{\prime} \sim 9 \mathrm{kN} / \mathrm{m}^{3}$, a soil buoyancy of $\sim 13 \mathrm{~N}$ would be expected, allowing the assumption that the displaced sediment volume equals the penetrometer volume below the seabed surface (Aubeny and Shi 2007). For a matching deployment, a sediment resistance force of $\sim 1080 \mathrm{~N}$ was measured, meaning that the estimated soil buoyancy represents only $\sim 1 \%$ of the sediment resistance force experienced by the penetrometer. The deepest penetrations during this survey reached $\sim 100 \mathrm{~cm}$ into fine sediment. Assuming a clay with $\gamma^{\prime} \sim 6 \mathrm{kN} / \mathrm{m}^{3}$, and that the penetrometer would displace the volume of sediment equaling its own volume plus a cylindrical hole of the same maximum diameter (Aubeny and Shi 2007), a soil buoyancy of $\sim 39 \mathrm{~N}$ would be reached. During a deployment of similar penetration depth into a soft clayey sediment, the maximum deceleration of the penetrometer 
was limited to $5.5 \mathrm{~g}$, leading to a sediment resistance force of only $\sim 347.6 \mathrm{~N}$. Soil buoyancy would then represent $11 \%$ of the sediment resistance force. This is in the range of other uncertainties when it comes to the estimate of sediment strength, and will be neglected in this study. Thus, the assumption is made that the experienced sediment resistance is a measure of the sediment's strength and bearing capacity for each soil layer that is penetrated. The sediment resistance against penetration of the probe was calculated using Newton's second law assuming that the measured negative change of acceleration (being referred to as deceleration hereafter) during sediment impact and penetration (dec) was entirely a consequence of sediment resistance $\left(F_{s r}\right)$ :

$$
F_{s r}=m_{b} d e c,
$$

with $m_{b}$ being the submerged weight of the probe. Pore pressure increase was small during the penetration of the probe, often even subhydrostatic (Fig. 4; Stark et al. 2015b).

Based on these assumptions, the maximum load before failure, and thus, an equivalent of bearing capacity was estimated by consideration of the surface area the sediment resistance force is working against. In this case, the projected surface area $\left(A_{p}\right)$ for the hemi-elliptic nose was used with $A_{p}$ changing with penetration depth for the length of the hemi-elliptic tip:

$$
q_{d y n}=\frac{F_{s r}}{A_{p}} .
$$

The use of the projected area may lead to slight overestimates of the load, as it is noticeable smaller than the actual tip mantle surface area. However, considering that most resistance will be opposed vertically against the probe justifies this assumption (Aubeny and Shi 2007). Finally, a strain rate correction needs to be considered, due to the high impact velocities which are significantly higher than standard geotechnical cone penetration tests. Here, the method by Dayal et al. (1975) was chosen to estimate the quasi-static bearing capacity (qsbc) (Stark et al. 2011a, 2012b):

$$
q s b c=\frac{q_{d y n}}{F a c}
$$


where $F a c=1+K \log _{10}\left(\frac{v}{v_{0}}\right)$

and an empirical factor $K$ ranging from 1-1.5 based on the results by Stoll et al. (2007), Stark et al. (2012b), and Stephan et al. (2015) for high velocity impact penetrometers. $K$ is expected to depend on the soil type and behavior during penetration. However, one goal of the application of the lightweight free fall penetrometer is to derive sediment information in areas that are hardly accessible to other geotechnical in-situ testing or more sophisticated sediment sampling tools. Thus, the inclusion of sediment-dependent factors should be as little as possible. For this study, penetrometer profiles will be analyzed for the full range of $K=1-1.5$, and results will be shown as full range or average with approximately $\pm 15 \%$ uncertainty. The impact of this uncertainty on the results will be further discussed later in the manuscript. A reference velocity $v_{0}=2 \mathrm{~cm} / \mathrm{s}$ was chosen based on standard cone penetration testing (e.g. Lunne 2010). This calculation was conducted for every data point and the respective penetration velocity $v$ determined by single integration of the measured deceleration over time. Penetration depth was calculated by integration of penetration velocity over time. Profiles of $d e c, v$, and $q s b c$ versus penetration depth were plotted to determine possible sediment stratification. Maximum $d e c$ and $q s b c$ in the upper meter of the seabed surface was used to spatially map differences in sediment strength.

Approximately 200 locations were tested in three different areas around the island: in the Workboat Passage between Herschel Island and the Yukon mainland, along the southeast shoreline of Herschel Island (Thetis Bay) including Pauline Cove, and around Collinson Head (Fig. 1). The data set is supported by bathymetric data, and backscatter data suggesting different sediment types from their acoustic reflectivity acquired in 2012 with a $500 \mathrm{kHz}$ GeoSwath Plus, a phase measuring bathymetric sonar (Kongsberg Geoacoustics). Backscatter data processing was carried out with Kongsberg Geoacoustics Geotexture. Furthermore, sediment samples were gathered using a Van-Veen grab sampler and a hand-held gravity 
corer while penetrometer surveying. The data set is complementing a larger data set of sediment samples and cores that were collected during previous expeditions (2012 and 2013) (Radosavljevic et al. 2016). Shoreline and thaw slump activity has been documented since the 1950s (Lantuit and Pollard 2008; Radosavljevic et al. 2015).

\section{Results}

The BlueDrop penetrometer performed well in the harsh environment. Limitations of battery life in the cold conditions were not noticed. The probe was continuously logging for up to 8.5 hours per survey day, and was recharged within approximately five hours. Despite deployment from a small vessel and choppy conditions, no disturbed or inclined impacts were noted. Wave motion was noticed in the deceleration record during handling on board and fall through the water column (Fig. 3). However, such fluctuations were limited to $\leq 0.1 \mathrm{~g}$. The only penetrometer profiles that were omitted from the analysis corresponded to deployment error (e.g., rope got tangled), leading to an abrupt and early stop, or an inclined impact. Impact into the seabed can be identified in the continuous acceleration records by a distinct deceleration of the probe (Fig. 3). Identification of the point of impact can be complicated by very soft surface sediments, hydrodynamics (particularly at limited water depths and wave action), and the fact that in shallow waters the probe may still be accelerating, or rope drag is prohibiting a perfect terminal velocity. An example for such a deployment is shown in Figure 3, showing the data of two independent accelerometers and the pressure transducer (for scale, the pressure was divided by 10). The different phases of deployment are clearly reflected in the recordings. Instability of the vessel in waves is reflected in the acceleration during the phase of the probe on board (light gray shading in figure 3). Noise in the acceleration record during fall through the water is associated with wave action at the shallow water depth. The noise stops immediately with impact into the seabed. Impact into seabed was in such cases 
identified by a change in deceleration gradient, and an immediate stop in noise associated to the fall through shallow water. Additionally, a deviation of hydrostatic pressure is mostly going along with the embedment of the pore pressure filter ring $(\sim 8 \mathrm{~cm}$ delayed with regard to the first tip contact with the seabed).

The water depths ranged from 0.5-11.4 $\mathrm{m}$ (4.35 $\mathrm{m}$ on average). The impact velocities varied according to variations in water depths from $3.5-7.3 \mathrm{~m} / \mathrm{s}$ with on average $5.9 \mathrm{~m} / \mathrm{s}$. Inclination of the penetrometer during penetration was limited to $\leq 8^{\circ}$. This does not require a correction of the results (O'Loughlin et al. 2014). Three deployments were significantly tilted, and were rejected from further analysis early on. Penetration depths reached from 0 to $98 \mathrm{~cm}$, and the maximum deceleration reached from $4.1 \mathrm{~g}$ to over $250 \mathrm{~g}$ at which values the accelerometers maxed out. The corresponding estimated quasi-static bearing capacity $(q s b c)$ reached maxima of $13-2613 \mathrm{kPa}$ for the results within the measurement range of the accelerometers. The penetration signatures also varied significantly in profile shape. Figure 4 shows four exemplary penetrometer profiles from waypoints (WPs) 793 and 802 in Pauline Cove, and WPs 774 and 787 at Collinson Head. The impact velocities equaled 5-6 m/s at each location. At WP 793 (Fig. 4A), the probe penetrated $58 \mathrm{~cm}$ showing a steadily increasing deceleration of the probe with a maximum of $4.1 \mathrm{~g}$ corresponding to a $q s b c \approx 13$ $\mathrm{kPa}$. No significant stratification was observed. Excess pore pressures were consistently negative during penetration, and reached a minimum of $\Delta u_{m}=-0.8 \mathrm{kPa}$. At WP 787 (Fig. 4B). The penetrometer reached a maximum penetration depth of $25 \mathrm{~cm}$, and a maximum deceleration of $15.9 \mathrm{~g}$, leading to an estimate of $q s b c \approx 52 \mathrm{kPa}$. The profile was characterized by two different gradients of deceleration and $q s b c$ with regard to sediment depth (Fig. 4B), changing abruptly at $8 \mathrm{~cm}$ and indicating a soft, less resistant top layer of $8 \mathrm{~cm}$ in thickness. Such a soft top layer in coastal environments is often related to active hydrodynamics reworking the top sediment (Stark and Kopf 2011; Stark et al. 2011a). Alternatively, such 
layers can represent a recent deposition of sediments which have not consolidated yet (Stark et al. 2011a; Stark et al. 2015b). The pore pressure response was fairly complex here, with the excess pore pressure being approximately zero until $q s b c \sim 10 \mathrm{kPa}$. With increasing strength of the sediments, the excess pore pressure increased with fluctuations to $\Delta u_{m} \sim 1 \mathrm{kPa}$, before the excess pore pressure became subhydrostatic shortly before the penetrometer came to a halt. Some sites were characterized by small penetration depths, large deceleration and a strong sediment resistance (Fig. 4C). At the shown location (WP 774) at Collinson Head, a stiff gravelly mud was sampled, leading to $q s b c \approx 515 \mathrm{kPa}$ at a penetration depth of only $4.5 \mathrm{~cm}$. At other locations even higher decelerations and estimates of sediment strength were obtained. Possible reasons will be discussed later. Multiple layers of different sediment resistance were observed at some sites such as at WP 802 (Fig. 4D). Here, the maximum deceleration reached just $5.4 \mathrm{~g}$, corresponding to $q s b c \approx 17 \mathrm{kPa}$, at a penetration depth of 76 $\mathrm{cm}$. The sediment opposed a very low resistance $(q s b c<1 \mathrm{kPa})$ against the probe in the uppermost $15 \mathrm{~cm}$ of sediment depth. At a sediment depth of $15-30 \mathrm{~cm}$, the sediment strength increased significantly to $q s b c \approx 10 \mathrm{kPa}$, and exhibited the same strength over the underlying $18 \mathrm{~cm}$ (sediment depth 30-48 cm). Then the sediment strength increased again, until the probe came to a rest (Fig. 4D). The profile suggested a reworked loose top layer similarly to the one observed at WP 787 (blue shade in Fig. 4B and 4D). Then the sediment strength increased significantly with depth, being similar to the observed increase in sediment strength as observed at WP 793 (Fig. 4A). However, differently than at WP 793, the penetrometer experienced an approximately constant resistance at sediment depths of $30-48 \mathrm{~cm}$, before sediment strength increased steadily with sediment depth again.

The significant differences in the penetrometer profiles indicated strong variations in the recent sediment deposition, consolidation and remobilization history. In the following section, the results were organized with regard to three areas: i) Thetis Bay, stretching from 
Pauline Cove to and slightly beyond Osborne Point, ii) Collinson Head including the offshore side of Simpson Point, and iii) Workboat Passage between Avadlek Spit, Osborne Point and the mainland (Fig. 1). It was attempted to explain the penetrometer signature by comparing it to sediment samples, echo sounder backscatter intensity, and the surrounding geological features.

\section{Thetis Bay}

Preliminary BlueDrop results from Pauline Cove were presented by Stark et al. (2015a). In the following, the results will only be briefly summarized. Penetration depths ranged from 11-85 cm, while the measured deceleration reached only 4-15 $\mathrm{g}$. This corresponded to estimates of quasi-static bearing capacity between 17-46 $\mathrm{kPa}$, representing overall soft to moderately stiff sediments. Most profiles indicated sediment stratification in the upper meter of the seabed surface with a top layer of distinguishably less strength than the underlying substratum (similar to WP 787 in Fig. 4B). This top layer ranged in thickness from $3-17 \mathrm{~cm}$. In some cases, three layers were identified (similar to WP 802 in Fig. 4D). The stratification was also reflected in the pore pressure response (Stark et al. 2015b), supporting that these layers differed in geotechnical characteristics. The texture of sediment samples from Pauline Cove indicated mud (classified based on Folk 1954) in the center of the cove with a median grain size of $d_{50} \approx 45 \mu \mathrm{m}$ (Fig. 5). Close to the shore, sediments were described as gravelly sandy mud $\left(d_{50}=45-80 \mu \mathrm{m}\right)$, as well as muddy sands $\left(d_{50}=149-326 \mu \mathrm{m}\right)$ in the vicinity of the beaches. A correlation between the estimated $q s b c$ and sediment classes based on interpolation of the sediment samples over the survey area is provided in Figure 6. The image of the multi beam echo sounder (MBES) backscatter intensity suggested a homogeneous sediment surface in the center of the cove, and showed some stronger reflectivity approaching the shores (Fig. 7). 
Three transects crossing Pauline Cove in its entrance area were measured in addition to the above summarized data: Pauline-Cross 1 WP793-799, Pauline-Cross 2 WP800-806, and Pauline-Cross 3 WP757, 807-802 (transects P1-P3 in Fig. 7). Along Pauline-Cross 1, the measured deceleration-sediment depth profiles were similar, often indicating a very soft top layer in thickness of 5-12 $\mathrm{cm}$ and in some cases another layer before entering the substratum where the probe came to rest. The corresponding $q s b c$ ranged between $13-26 \mathrm{kPa}$. Figure 7 shows the spatial distribution with regard to the maximum $q s b c$, showing mostly soft sediments. In relation to the water depths, $q s b c$ values of $\approx 18-26 \mathrm{kPa}$ were observed at shallow water depths with a slight increase with increasing water depth, while sediments were significantly softer at water depths $>5 \mathrm{~m}$ (Fig. 8). The deepest top layer thickness (including top layer 1 and 2 if applicable) were associated to the water depths at which the highest resistance was measured (Fig. 8). This may indicate that top layers 1 and 2 were thick and not fully penetrated at the other sites, and thus were characterized by thicker fine sediment deposits. Along Pauline-Cross 2, penetration depths ranged between $24-85 \mathrm{~cm}$. The measured deceleration reached from $4.4-63.8 \mathrm{~g}$, and top layer thicknesses ranged from 8-35 $\mathrm{cm}$. The spatial distribution of maximum $q s b c$ indicated soft sediments across the transect. The measurement location closest to the island shore (WP800) was characterized by slightly stiffer sediments, similarly to Pauline-Cross 1, and the location closer to the spit tip (WP806) showed a strong sediment resistance (Fig. 7). This observation was supported by the results from the Pauline-Cross 3 transect. Here, hard sediments extended from the sandy-gravelly spit (Fig. 7). Interestingly, hard sediments reached noticeably farther into the bay than coarse and strongly reflecting sediments were noticed in the sonar's backscatter intensity (Fig. 7). This is related to sediment layering. Even if only a thin layer of fine sediments is covering coarser and harder sediments, this will remain undetected by the sonar that is restricted to measuring the seabed surface. Sediments were very soft at the remaining locations towards 
the island shore. Penetration depths along this transect equaled 16-62 $\mathrm{cm}$, and top layer thicknesses equaled 4-17 cm with a decreasing thickness towards the island shore. Sediment samples corresponded mostly well to the penetrometer signatures with low decelerations and $q s b c$ values, suggesting fine and soft sediments, while harder impacts suggested sand and gravel (Figs. 5 and 6).

Five cross-shore transects and two long-shore transects were measured in Thetis Bay (Fig. 9). Water depth along the cross-shore transects ranged from 1 to $10 \mathrm{~m}$. The water depth along long-shore transect 1 ranged from 1 to $4 \mathrm{~m}$, and along long-shore transect 2 from 2 to 6 m. Penetration depths, deceleration and sediment strength profiles varied significantly with regard to the cross-shore and long-shore location. Overall, the following observations can be made: (i) Soft sediments were found in the East of Thetis Bay (Fig. 9A). This included locations in front of the easternmost of the active retrogressive thaw slumps in Thetis Bay, and is well reflected in the smooth sonar images and the grab samples (Fig. 9). (ii) The sediment strength varied significantly along shore from East of Thetis-Cross 1 going westwards past Thetis-Cross 5 (Fig. 5). This included some impacts on a very hard surface without any noticeable penetration depth at and just East of Thetis-Cross 4. Overall, these deployments were located in an area of hetereogeneous seabed reflections that are likely associated to larger clasts being deposited here from the nearby river outflow (Fig. 9). However, a direct match of the specific sites could not be established. This may be related to temporal variations of exposure and burial of such large clasts and possibly diamicton during changes of hydrodynamic activity. It has to be noted that the penetrometer data and the sonar data were collected in different years. Sediment grab samples indicated an overall coarsening to sands in the area, but did not reflect these strong spatial variations (Fig. 9). However, it was noted that only a limited number of grab samples exist from this areas, as the sampler came up mostly empty, suggesting coarse clasts or dense diamicton presence. Some single 
softer sites were recorded in front of the large Slump D retrogressive thaw slump (Fig. Fig. ). While this was also reflected in the sonar's backscatter intensity, this cannot be identified in the retrieved sediment samples (Fig. 9). (iii) Overall, softer sediments were associated to water depths in excess of $6 \mathrm{~m}$. Figure 8 displays the measured deceleration-penetration depth profiles along Thetis-Cross 4, with WP736 being the closest to the shore at a water depth of $2 \mathrm{~m}$, and WP831 being the furthest offshore with a water depth of $\sim 7 \mathrm{~m}$. The correlation of maximum quasi-static bearing capacity and top layer thickness to water depth yielded sediment softening and top layer thickening with increase in water depth. This trend is not visible in the sonar images, but can be identified in the sediment samples (Fig. 9, Tab. 1).

The western parts of Thetis-Long 1 and 2 were characterized by stiff and coarse sediments (Fig. 5). Penetration depths were $\leq 16 \mathrm{~cm}$, the maximum decelerations $>66 \mathrm{~g}$, and the quasi-static bearing capacities were estimated to be $>190 \mathrm{kPa}$. In most cases, sediments were slightly looser and softer close to the shore, likely being reworked by waves. Most sediments were sands (Figs. 5 and 9, Tab. 1).

\section{Workboat Passage}

The Workboat Passage is enclosed by the mainland, Avadlek Spit and Osborne Point two spits attached to Herschel Island (Fig. 1). The water depths are mostly shallow with 1-7 $\mathrm{m}$, only in the channel between the tip of Avadlek Spit and the mainland water depths exceed $10 \mathrm{~m}$. Sediments were predominantly stiff with $80 \mathrm{kPa}<q s b c<250 \mathrm{kPa}$ (Fig. 5). Slightly softer sediments were found at locations WP160 and WP163 in the central South-east of the passage. The slight softening is not reflected in the sample material (Fig. 5). Significantly softer sediments with maximum deceleration $<14 \mathrm{~g}$ and estimates of $q s b c \leq 42 \mathrm{kPa}$ were only measured at WP147-148 in the shelter of Avadlek Spit (Fig. 5). While sediment samples suggested significant sediment fining towards the Northwest corner of Workboat Passage 
(Fig. 5), this cannot be directly correlated to the penetrometer results, possibly indicating temporal variations of the location of fine sediment deposits with active sediment dynamics. No sonar surveying was conducted here that could have revealed more detail on the migration of larger fine sediment deposits.

\section{Collinson Head}

Nine cross-shore transects were surveyed from Simpson Point around Collinson Head to the Northeastern side of the island (Fig. 7). Water depths along the transects reached from 3 to $11 \mathrm{~m}$, increasing in the offshore direction. Soft sediments to very hard impacts were registered. The transects Collinson 1-6 were characterized by hard sediments close to the shore, and softer sediments offshore (Fig. 7). Figure 10 displays the deceleration-penetration depth profiles along transect Collinson 1. Stiff sediments $(101 \mathrm{~g})$ under a thin loose top layer were encountered at WP759 in a water depth of $\sim 9$ m close to the shore. Going offshore, the soft top layer thickness increased to $\sim 5 \mathrm{~cm}$ and the maximum deceleration was significantly smaller (36 g) at WP760. Further offshore at WPs 761-762, the sediment resistance was small $(<6 \mathrm{~g})$, and the top layer thickness remained $\sim 4 \mathrm{~cm}$ (Fig. 10). Thus, sediment strength decreased significantly, and top layer thickness slightly increased with distance from the shore. The decrease in sediment strength was directly related to dominant sediment fining in the offshore direction (Fig. 5).

Offshore sediment softening was also observed north of Collinson Head (Collinson 9 in Fig. 7), but the two transects measured radial to Collinson Head (Collinson 7-8) differed. Here, water depths ranged from 5 to $11 \mathrm{~m}$, and penetration depths from 19 to $29 \mathrm{~cm}$. The maximum decelerations ranged from 13 to $23 \mathrm{~g}$, and the respective estimate of $q s b c$ from 52 to $87 \mathrm{kPa}$. The deceleration-penetration depth profiles reached similar values, but varied with regard to the top layer thickness (Fig. 10). A thin top layer $(2 \mathrm{~cm}$ ) was detected close to the 
shore along Collinson 7. It increased to $8-10 \mathrm{~cm}$ in the following two deployments going offshore, before it decreased again at the farthest location from the shore. During the deployments, the field crew noted that the penetrometer was difficult to pull out of the sediment at the locations at Collinson Head. Traces of mud with gravel were found sticking to the penetrometer upon retrieval. No sediment samples or sonar images were retrieved at this location.

\section{Discussion}

A large number of deployments were carried out in only four survey sessions of each approximately 4 hours, excluding longer transit distances. Despite cold temperatures and sometimes large temperature differences between air and water temperature, the penetrometer's Ni-Cd battery performed well over the anticipated duration of operation. This allowed the full mobilization of the probe on land without a need to access any electric ports or switches in the Zodiac. Hard impacts were encountered, but did not damage the probe. No zero drift was recorded with temperature variations between water $\left(\sim-1^{\circ} \mathrm{C}\right)$, air $\left(3-14^{\circ} \mathrm{C}\right)$, and room temperature. Penetration depths were limited $(<1 \mathrm{~m})$, which is typical for lightweight free fall probes (Stoll and Akal 1999; Stark and Wever 2009; Stark et al. 2014). The addition of extra weights to increase penetration depth was not attempted, as the research focused on surface sediment processes, and no winch was available for recovery. The probe, including supporting equipment and maintenance materials, fitted into a standard suitcase size case, and was flown as check-in luggage, and for the last transit to Herschel Island, with the two people surveyor team in a Cessna-170 water plane. The survey demonstrated the suitability, the durability and the flexibility of the operation of portable free-fall penetrometers in cold and logistically challenging conditions. 


\section{Geotechnical characteristics and stratification}

Sediment type classification was one research objective, aiming for complementing the sediment distributions derived from grab sampling and ground truth observations derived from acoustic reflectivity. Stoll et al. (2007), and Stark and Wever (2009) suggested that the general soil type can be derived directly from the deceleration records of projectile-like free fall penetrometers. Mulukutla et al. (2011) proposed a firmness factor that relates to deceleration and penetration depth. Stark et al. (2012a) was able to correlate median grain size of sands directly to values of $q s b c$.

A concern during the calculation of the $q s b c$ is the choice of the empirical factor $K$. Due to the fact that $K$ is expected to vary with sediment type, a specific choice of $K$ for an unknown sediment was not attempted. This could have been tried during post-processing using the sediment sample results. However, one defined goal of the use of the lightweight penetrometer in an environment as the Arctic nearshore zone was to derive conclusions independent from more detailed sediment information, particularly in challenging areas where sediment sampling even with simple methods such as grab samples represents a significantly larger effort, which is also reflected in the lower number of sediment samples that were collected over two field seasons. Furthermore, no accurate calibrations of $K$ exist for high impact velocity penetrometers, particularly of projectile-shape, to cover the large variety of sediment mixtures encountered here. To improve this issue, a detailed calibration series for a variety of soil types is planned using a large, modified Cone Penetration Test calibration chamber. A goal for these tests is to relate $K$ to a property measured directly by the penetrometer (e.g., a combination of deceleration over penetration depth and/or pore pressure). For the current data set, an uncertainty in quasi-static bearing capacity of about $15 \%$ results from the uncertainty related to $K$, allowing the ranging of $K$ based on studies by Stoll et al. (2007), Stark et al. (2012) and Stephan et al. (2015) for high velocity impact 
penetrometers. It should also be noted that a different choice of $K$ would have little impact on the final conclusion drawn in this study, which are also supported by the measured deceleration records (Stoll et al. 2007; Stark and Wever 2009).

In Fig. 11, the median grain size as well as the textural main sediment description (mud, sand) based on sediment grab samples was correlated to the estimated maximum quasi-static bearing capacity. In Fig. 12, the $q s b c$ at a penetration depth of $10 \mathrm{~cm}$ (being a representative depth of sediment sampled using a hand-deployed grab sampler) were correlated to gravel, sand and mud content, as well as median grain size. Sediment strength at a sediment depth of $10 \mathrm{~cm}$ is often affected by sediment dynamics (Stark and Kopf 2011). This leads to overall very low values of $q s b c$ for muds, and some scatter for sand. Higher values for mud were associated to in one case a relatively high sand content approaching $48 \%$, and cannot be explained for the other case. Due to this impact of sediment transport processes, maximum values of $q s b c$ per deployment were used for further analysis. The scatter in Figure 11 was not noticeably improved by using the ratio of $q s b c$ over penetration depth instead of $q s b c$, or sand and mud content instead of $d_{50}$. Thus, the observed scatter in Figure 11 is likely reflecting layers of different state of consolidation. Muds were limited in their variety in median grain size with $d_{50}=45-60 \mu \mathrm{m}$, but varied more significantly in strength $q s b c=20-202$ $\mathrm{kPa}$. A large number of the penetrometer deployments on muds fell into the range of $q s b c=$ 20-40 $\mathrm{kPa}$ (maximum deceleration 6-12 $\mathrm{g}$ ), being in good agreement with results for muddy sediments measured by Stark et al. (2011b) using the Nimrod penetrometer, and Stoll and Akal (1999) and Stark and Wever (2009) using the Expendable Bottom Penetrometer (XBP). Using the method suggested by Aubeny and Shi (2006) for the XBP to derive a bearing factor and the undrained shear strength $c_{0}$ for soft marine clays resulted in $c_{0} \approx 1.5-3.5 \mathrm{kPa}$ for the deployments with $q s b c=20-40 \mathrm{kPa}$. This estimate of shear strength matches well the expected sediment strength for soft marine muds (e.g., Aubeny and Shi 2006). 
Figure 13 shows the relationship between $d_{50}$ and penetration depth for locations at which penetrometer deployments and sampling was conducted. In accordance with the $q s b c$, penetration depths were scattered for muddy sediments. The two sites with very low penetration depths can be explained with impacts into single cobbles or debris. Such single coarse particles would unlikely be collected with the small sampler. For sandy sediments, penetration depths decreased with coarseness. This is also consistent with the observed increase in $q s b c$.

For the deployments in areas characterized by muddy samples with $q s b c>40 \mathrm{kPa}$, the $q s b c$ - penetration depth profiles revealed hard sediment (likely sand) under a muddy top layer in the order of centimeters to tens of centimeters. An example is location WP 808 with $d_{50}=50 \mu \mathrm{m}$. Here, two layers of soft (likely muddy) sediments reached to a penetration depth of $18 \mathrm{~cm}$, before the penetrometer hit a hard layer ( $q s b c \approx 200 \mathrm{kPa}$ ) (Fig. 14), indicating well compacted sand that represents an extension of the hook at Simpson Point spit that was more recently covered by fine sediment deposits (Figs. 5 and 7). The sediment sample indicated gravelly sandy mud. In these cases, the grab sample likely consisted mostly of the muddy surface layer, and did not reflect the closely underlying sand layer. Similar layering and the mismatch between samples and measured maximum strength was particularly observed in locations that represented a transition from dominantly sandy to muddy sediments (Figs. 5 and 11).

The sampled sands were mostly fine, but showed as well a broad range of strength, and a trend towards higher sediment strength with coarsening of median grain size within the sandy fractions (Figs. 6 and 11). Figure 6 however suggests that hardest impacts were noticed for fine sands compared to medium sand. This is consistent with the findings by Stark et al. (2012a) who found that increasing grain size in sandy fractions resulted in decreasing strength due to denser sand particle packing of the fine sand. A plausible explanation for the 
softening with sediment fining from fine sands to clay is the relevance of mud content. This matches well suggestions by, e.g., Stoll and Akal (1999); Stark and Wever (2009); and Mulukutla et al. (2011) who suggested an increase in sediment resistance with increasing grain size when transitioning from mud to sand. However, when the $q s b c$ versus the samples' mud, sand and gravel fractions are compared (Fig. 12), a significant variability of $q s b c$ was observed even within sand samples of similar mud content. Gravel content appeared negligible (Fig. 12 upper left panel), and it should be noted that gravel content was not determined in one of the sediment sample datasets (Radosavljevic et al. 2016). Gravel was sampled only at one location featuring an expected high $d_{50}=344 \mu \mathrm{m}$, but a moderate to low sediment strength $q s b c=54 \mathrm{kPa}$. This can be explained by the fact that the gravel had a significant mud content, and gravel at the seabed surface often lacks the dense packing of sands (Stark et al. 2013).

Another explanation for differences in $q s b c$ within one sediment group may be the penetration depth. In accord with Terzaghi's bearing capacity theory, bearing capacity will increase with increasing shear strength at deeper penetration depths if the sediment is normally consolidated (Terzaghi 1943; Randolph and Gourvenec 2011; Jia et al. 2013; Wiemer et al. 2015). However, this factor unlikely impacted the sandy sediments, as penetration depths were consistently small $(<10 \mathrm{~cm})$ for $d_{50}>125 \mu \mathrm{m}$, and ranged between 7 $-22 \mathrm{~cm}$ for $50 \mu \mathrm{m}<d_{50}<125 \mu \mathrm{m}$. Thus, while the overall sediment type can be directly derived from the penetrometer results and even median grain size of the sandy fractions can be correlated to the estimated strength, the penetrometer results were not solely dependent on sediment type and particle size distribution. Also reflected were other geotechnical parameters of the soil influencing the shear strength, being likely the bulk density and the state of consolidation. This can result from differences in the sediment deposition history, 
related to the prevailing hydrodynamic conditions and sediment deposition events (Stark and Kopf 2011).

Four typical vertical profiles of sediment strength and resistance were identified in the uppermost meter of the seabed surface in Herschel Island's nearshore zone (Fig. 4): i) An approximately steady increase in sediment strength and deceleration of the probe with depth (Fig. 4A). Maximum values of sediment strength and deceleration were often small for these profiles, and the penetration depth high. This suggested a thick, but loose muddy sediment top layer of poor consolidation, likely associated to large and recent events of sediment deposition. This was only observed in well sheltered areas in Pauline Cove. ii) More common were profiles featuring a loose top layer over stiffer substratum (Fig. 4B-D). Such a thin (in the order of centimeters to tens of centimeters) sediment top layer is often associated to either a mobile or active sediment layer that is frequently or recently reworked by energetic hydrodynamic conditions, or to a volume of sediment that was recently deposited and has not achieved a similar consolidation as the underlying material, for the case that both layers are of similar sediment type (Stark and Kopf 2011). Another option is the deposition of fine material on a harder surface or sediment type. The latter is likely the case at WP774 (Fig. 4C) where a hard material was encountered under only $1 \mathrm{~cm}$ of looser material. The sediment sample revealed gravelly sand. Thus, the profile can be explained best by a densely packed gravelly sand that allowed some limited penetration in the order of centimeters before bringing the probe to a halt, likely covered here by a thin sand layer that is mobilized regularly by waves. Such coverage would also explain the patchiness of high reflectors (gravel) and finer sediments in this backscatter intensity image of the region (Fig. 9). A hard underlying surface such as bedrock or ice-bearing permafrost is unlikely, as it would have brought the penetrometer to an abrupt stop. The observed top layer at WP787 is significantly thicker $(8 \mathrm{~cm})$, and the strength of the underlying material did not exceed $q s b c \sim 50 \mathrm{kPa}$, 
indicating a finer substrate. While no sediment sample was extracted at this location, the sediment interpretation is feasible based on the mixed sediments observed in the region. The top layer can be expected to be of a similar material, and to be subject to frequent reworking, due to the energetic nature of the wave climate here, being also reflected by the significant erosion of Collinson Head (Radosavljevic et al. 2015). The thickness of this layer is in good agreement to similar layers resulting from reworking of the sediment surface by waves (Stark and Kopf 2011). WP 808 indicated a combination of both scenarios showing an $18 \mathrm{~cm}$ thick mud layer on sand, with the upper $10 \mathrm{~cm}$ being very soft and likely reworked by waves refracting around Simpson Point (Fig. 14).

Geotechnically more interesting are the profiles of type (iii) that indicated multiple sediment layers (e.g., Fig. 4D). The most intuitive explanation for the observed "weak" layer is a change in sediment type (red shading in Fig. 4D). However, the over- and underlying material characteristics indicated already very soft and muddy sediments which is also confirmed by sediment sampling in the area. Thus, a softer sediment type is unlikely, and the question arises why this mud layer differed in sediment resistance compared to other layers? Recent sedimentation or mobilization due to hydrodynamic activity is unlikely due to its sediment depth. The characteristics of the layer in question may be related to processes of freeze and thaw. Kurfurst and Dallimore (1990) pointed out that most nearshore sediments at a distance of 1-4 km around land areas feature shallow permafrost at less than $10 \mathrm{~m}$ below the seabed surface. Furthermore, they found that sediments at a water depth of less than $1.7 \mathrm{~m}$ are susceptible to winter freezing. Stevens et al. $(2009,2010)$ reported even shallower values from the apex of the Mackenzie Delta area. Kurfurst and Dallimore (1990) also found that thawing of pre-Holocene sediments in water depths $>2 \mathrm{~m}$ may result in a rapid loss of soil strength. While in-situ geotechnical sediment studies particularly of the nearshore seabed surface are still rare, a number of researchers have addressed the impact of freeze-thaw cycles 
on soil in the laboratory. Aubert and Gasc-Barbier (2012) found that clay blocks underwent a process of desiccation over multiple freeze-thaw cycles leading to the development of microcracks that later could be filled with water. Qi et al. (2008) documented that the cohesion decreased over freeze-thaw treatment if the soil exceeded a critical dry unit weight. This means that soil may densify and strength may increase if the soil is loosely packed, and soil may dilate and loose strength for denser packed soils. None of these studies explain directly the observations in the nearshore zone of Herschel Island, but it can be hypothesized that the measured weak layer is associated to the expansion of pore space, and thus, decrease in cohesion and sediment strength following freeze and thaw. Another explanation for the weak layer may be gassy sediments. This hypothesis was already stated based on the pore pressure dissipation records in the same region (Stark et al. 2015b), and weak sediments resulting from gassy sediments have been documented by many authors (e.g., Seifert et al. 2008). Gas hydrates and gassy sediment weak layers were identified at the Beaufort Sea continental margin (Kayen and Lee 1991). While these investigations were conducted at significantly deeper water depths, gassy sediments cannot be excluded as a plausible explanation here. Overall, it seems likely that the sedimentation history, and thus, mud slump activity governed the spatial location of this weak layer (WP 808 in Pauline Cove, water depth $2.7 \mathrm{~m}$, and sediment depth $31-48 \mathrm{~cm}$ ). More detailed investigations are needed to understand the processes that led to the development of this weak layer.

The fourth type of profile represented direct hard impacts with $q s b c>500 \mathrm{kPa}$ at the immediate seabed surface or under a thin layer of 1-3 cm. Stark et al. (2013) showed that gravel does not lead to such impact signatures, and bedrock is not abundant. Thus, it may be argued that large clasts or a very shallow permafrost layer were impacted here. The latter is unlikely due to the shallow penetrations of less than $10 \mathrm{~cm}$ where no permafrost is expected. Larger clasts may be deposited in the nearshore zone by the nearby outflowing creeks (Fig. 
9). The data indicated that the central and western nearshore zone of Thetis Bay does not allow long-term accumulation of fine sediments, leaving potentially large clasts and diamicton exposed. However, more detailed investigations are needed to explain why this occurred particularly at these locations.

\section{Spatial distribution}

Storm conditions and large fetch events in the Southern Beaufort Sea are mostly associated to northwesterly winds (Lintern et al. 2013; Fig. 1). However, prevailing southeasterly winds (Fig. 1D) create significantly different hydrodynamic conditions, and occasional storms from this direction have also been reported (Lintern et al. 2013). This is also reflected in the direction of spits on along the SE exposed part of Herschel Island, where Simpson Point offers Pauline Cove good shelter. Furthermore, most retrogressive thaw slumps are located along Thetis Bay (Lantuit and Pollard 2008). It follows that the three surveyed areas: Thetis Bay, Collinson Head and Workboat Passage are exposed to significant differences with regard to possible factors influencing sediment erosion and distribution. Pauline Cove is overall characterized by soft, poorly consolidated and often stratified sediments (Fig. 5-7). It can be hypothesized that Pauline Cove is acting as a sediment sink. While the activity of thaw slumping within Pauline Cove (Lantuit et al. 2012), as well as coastal erosion due to wave action (Radosavljevic et al. 2015) is limited, longshore drift transports fine sediments introduced to Thetis Bay by thaw slumping and coastal erosion along the southern shores of Herschel Island to Pauline Cove. This hypothesis is also supported by the fact that very few soft sediments were detected close to the southern shoreline and in front or east of the retrogressive thaw slumps (Fig. 5). In consideration of the wind conditions and morphodynamics, this seemed to suggest that on the southeast oriented coast of Herschel Island, waves generated by northwesterly storms are refracted around 
Collinson Head, and together with prevailing southeasterly winds drive the evolution of the spits. Fine sediment introduced by retrogressive thaw slumps can be transported by weaker events, such as southerly currents and wave events of limited fetch towards Pauline Cove where they get trapped. These processes could selectively transport coarse and fine sediment fractions. This may also entail that the hook of Simpson Point's spit may grow on alternating fine and coarse sediments. During above described deposition events, fine sediments may be deposited on the submerged extensions of the hook, and may be covered by coarse sediments during the progradation of the spit terminus.

The eastern nearshore zone of Thetis Bay was characterized by soft sediment indicating deposition and abundance of fine sediments, likely associated to the same process as discussed for Pauline Cove. Further offshore sediments softened as expected for Arctic sediments outside of the nearshore zone at water depths approaching ten meters (e.g. Dallimore et al. 1988). In the nearshore zone, however, the sediments were stiff to very hard. Fresh soft sediment deposition appeared to be minor and isolated here. Sandy to gravelly sediments were found explaining some stiffness, but many sites indicated harder sediments than anticipated for the sampled sediment type (Figs. 5 and 9). In some cases, this was related to the specific grain size mixtures. However, the large variation of sediment strength over a narrow range of sediment classifications may be related to sediment densification following freeze and thaw (Qi et al. 2008), or possibly even the presence of ice lenses which would indicate that the frozen active layer was penetrated (Buteau et al. 2010).

Sediments in Workboat Passage were fairly stiff sandy sediments as suggested by the penetrometer results and samples. Sediments southeast of Avadlek Spit were soft, indicating deposition of sediments in the shelter of the spit, while the coarsening of sediments was accompanied by an increase in $q s b c$ (Fig. 5). 
Collinson Head showed a typical trend of hard, partially very stiff sediments nearshore and softening offshore (Figs. 5 and 7). Similar arguments as discussed previously can be applied here. It should be noted that the landfast ice extends from Collinson Head to Kay Point to the southeast due to the presence of Herschel Sill, a submerged gravelly bar (Fig. 1). The clockwise motion of the Beaufort Gyre results in a much greater degree of sediment reworking north of Herschel Sill (and Collinson Head). Soft sediments encountered here are delivered by longshore drift, with additions of gravel plucked offshore and off Herschel Sill (Pelletier 1987). This is supported by profiles Collinson 7-8 right at the head, and sediments sticking to the penetrometer were gravelly mud.

This study demonstrated that the BlueDrop free fall penetrometer is a valuable tool complementing other geophysical and conventional field methods and adding new information. Even though the method presented herein may provide clues to the depositional dynamics and shoreface evolution, the current study presents the foundation of an upcoming article. In the upcoming article the available information will be integrated into a conceptual model of sediment transport processes from coastal erosion and thaw slump activity to deposition and sediment consolidation. However, this effort necessitates the inclusion of additional data sources (e.g. meteorologic, geologic, geomorphologic, oceanographic data, etc.) that would be beyond the scope of the current study, where the primary motivation was to test the feasibility of the method. 


\section{Conclusions}

An in-situ geotechnical assessment of Arctic nearshore sediments was conducted during an expedition to Herschel Island, Yukon, in July-August 2014. In the larger context of the expedition, the type, characteristics, and stability of seafloor surface sediments were of interest in order to derive information about recent sediment erosion, deposition, and relocation processes. A portable free-fall penetrometer proved a valuable tool giving insight into sediment type, stratification, and the qualitative state of consolidation. The advantage of this tool is its ease of transport and performance in harsh conditions. The results obtained indicated distinct separations of sediment types. Fine and soft sediment was deposited further offshore, and especially in Pauline Cove, a local sediment sink. Surprisingly little fine sediment deposits were identified in front of some of the larger retrogressive thaw slumps in Thetis Bay, indicating that sediments are rapidly washed away from these locations. At some sites weak layers at a sediment depth of $30-50 \mathrm{~cm}$ were observed. While the cause of these weak layers cannot be confirmed here, their character may be explained by deposition of large sediment volumes in conjunction with a freeze-thaw history and/or gassy sediments.

The presented study showed the suitability of portable free fall penetrometers for in-situ geotechnical Arctic nearshore and shallow water investigations. However, the unique results also raised a number of questions and hypotheses which will have to be tested in follow-up expeditions, laboratory investigations, and publications. The results are of importance to better the understanding, prediction and possible mitigation of Arctic coastal erosion and subaqueous sediment transport, as well as for Arctic engineering activities in the nearshore zone including possibly wave energy harvesting and pipelines. 


\section{Acknowledgements}

The authors would like to thank the National Sciences Foundation for funding through NSF-IIA-142661. Furthermore, we would like to thank the YUKON14 field team for their amazing support, particularly Gavin Manson and George Tanski. H. Lantuit and B. Radosavljevic are supported by a grant of the Helmholtz Association (grant no. VH-NG-801). Special thanks go to the rangers of the Herschel Island Territorial Park for their outstanding support during surveying. We also acknowledge Stephen Smyth and Denise Patey and the BlueCDesigns team for technical support with the BlueDrop, and the Aurora Research Institute, Inuvik, for logistical support.

\section{References}

Aubeny, C. P., and Shi, H. 2006. Interpretation of impact penetration measurements in soft clays. Journal of Geotechnical and Geoenvironmental Engineering 132(6), pp. 770777.

Aubert, J. E., and Gasc-Barbier, M. 2012. Hardening of clayey soil blocks during freezing and thawing cycles. Applied clay science 65, pp. 1-5.

Brooks, J.D., and Lang, T.G. 1958. Hydrodynamic drag of torpedos. NAVORD report 5842. Underwater Ordnance Department, China Lake, California.

Buteau, S., Fortier, R., and Allard, M. 2005. Rate-controlled cone penetration tests in permafrost. Canadian Geotechnical Journal 42(1), pp. 184-197.

Buteau, S., Fortier, R., and Allard, M. 2010. Permafrost weakening as a potential impact of climatic warming. Journal of Cold Regions Engineering 24(1), pp. 1-18.

Burn, C. R., and Lewkowicz, A. G. 1990. Canadian Landform Examples - 17 Retrogressive Thaw Slumps. The Canadian Geographer/Le Géographe canadien 34(3), pp. 273-276. 
Burn, C. R., and Zhang, Y. 2009. Permafrost and climate change at Herschel Island (Qikiqtaruq), Yukon Territory, Canada. Journal of Geophysical Research: Earth Surface (2003-2012) 114(F2), F02001.

Cruden, D. M., and Martin, C. D. 2013. Assessing the stability of a natural slope. In Global View of Engineering Geology and the Environment, pp. 17-26.

Dallimore, S. R., Kurfurst, P. J., and Hunter, J. A. M. 1988. Geotechnical and geothermal conditions of near-shore sediments, southern Beaufort Sea, Northwest Territories, Canada. In Proceedings of the 5th International Conference on Permafrost, Trondheim, Norway 1, pp. 127-131.

Dallimore, S.R., Wolfe, S.A. and Solomon, S.M. 1996. Influence of ground ice and permafrost on coastal evolution, Richards Island, Beaufort Sea coast, NWT. Canadian Journal of Earth Sciences 33(5), pp.664-675.

Dayal, U., Allen, J. H., and Jones, J. M. 1975. Use of an impact penetrometer for the evaluation of the in-situ strength of marine sediments. Marine Georesources \& Geotechnology 1(2), pp.73-89.

DeJong, J. T., Frost, J. D., and Cargill, P. E. 2001. Effect of surface texturing on CPT friction sleeve measurements. Journal of geotechnical and geoenvironmental engineering, 127(2), pp. 158-168.

Folk, R. L. 1954. The distinction between grain size and mineral composition in sedimentaryrock nomenclature. The Journal of Geology, pp. 344-359.

Fritz, M., Grigoriev, M., Pedentchouk, N., Frederick, J., and Lantuit, H. 2015. Arctic LandOcean Interactions-Permafrost land-ocean interactions in the Arctic: from coastal to submarine permafrost including gas hydrates. Arctic in Rapid Transition. Doi: 10.2312/ART.0330.12145. 
Gardner, A. S., Moholdt, G., Wouters, B., Wolken, G.J., Burgess, D.O., Sharp, M.J., Cogley, J.G., Braun, C., and Labine, C. 2011. Sharply increased mass loss from glaciers and ice caps in the Canadian Arctic Archipelago. Nature 473(7347), pp. 357-360.

Günther, F., Overduin, P.P., Sandakov, A.V., Grosse, G. and Grigoriev, M.N. 2013. Shortand long-term thermo-erosion of ice-rich permafrost coasts in the Laptev Sea region. Biogeosciences 10(6), pp.4297-4318.

Harper, J. R. 1990. Morphology of the Canadian Beaufort Sea coast. Marine Geology 91: 7591. doi:10.1016/0025-3227(90)90134-6.

Jeanjean, P., Spikula, D., and Yoing, A. 2012. Technical vetting of free-fall cone penetrometer. In Offshore Site Investigation and Geotechnics: Integrated Technologies - Present and Future, 12-14 September, London, UK, SUT-OSIG-12-16.

Jia, R., Hino, T., Hamada, T., Chai, J., and Yoshimura, M. 2013. Density and undrained shear strength of bed sediment from ND-CPT. Ocean Dynamics 63(5), pp. 507-517.

Jones, B. M., Arp, C. D., Jorgenson, M. T., Hinkel, K. M., Schmutz, J. A., and Flint, P. L. 2009. Increase in the rate and uniformity of coastline erosion in Arctic Alaska. Geophysical Research Letters 36(3), pp. 1-5.

Jumikis, A. R. 1977. Thermal Geotechnics. Rutgers University Press, New Brunswick.

Kayen, R. E., and Lee, H. J. 1991. Pleistocene slope instability of gas hydrate-laden sediment on the Beaufort Sea margin. Marine Georesources \& Geotechnology 10(1-2), pp. 125141.

Kokelj, S. V., Smith, C. A. S., and Burn, C. R. 2002. Physical and chemical characteristics of the active layer and permafrost, Herschel Island, western Arctic Coast, Canada. Permafrost and Periglacial Processes 13(2), pp. 171-185. 
Kurfurst, P. J., and Dallimore, S. R. 1991. Engineering geology of nearshore areas off Richards Island, NWT: a comparison of stable and actively eroding coastlines. Canadian Geotechnical Journal 28(2), pp. 179-188.

Lantuit, H., and Pollard, W. H. 2005. Temporal stereophotogrammetric analysis of retrogressive thaw slumps on Herschel Island, Yukon Territory. Natural Hazards and Earth System Science 5(3), pp. 413-423.

Lantuit, H., and Pollard, W. H. 2008. Fifty years of coastal erosion and retrogressive thaw slump activity on Herschel Island, southern Beaufort Sea, Yukon Territory, Canada. Geomorphology 95(1), pp. 84-102.

Lantuit, H., Pollard, W. H., Couture, N., Fritz, M., Schirrmeister, L., Meyer, H., and Hubberten, H. W. 2012. Modern and late Holocene retrogressive thaw slump activity on the Yukon coastal plain and Herschel Island, Yukon Territory, Canada. Permafrost and Periglacial Processes 23(1), pp. 39-51.

Lawrence, D. M., Slater, A. G., Tomas, R. A., Holland, M. M., and Deser, C. 2008. Accelerated Arctic land warming and permafrost degradation during rapid sea ice loss. Geophysical Research Letters 35(11), L11506.

Lintern, D. G., Macdonald, R. W., Solomon, S. M., and Jakes, H. 2013. Beaufort Sea storm and resuspension modeling. Journal of Marine Systems 127, pp. 14-25.

Lunne, T. 2010. The CPT in offshore soil investigations-a historic perspective. In Proceedings of the 2nd International Symposium on Cone Penetration Testing (CPT'10), Huntington Beach, CA. Edited by Mitchell et al.

Marsh, P. and Neumann, N.N. 2001. Processes controlling the rapid drainage of two ice-rich permafrost-dammed lakes in NW Canada. Hydrological Processes 15(18), pp.34333446. 
Masselink, G., Hughes, M., and Knight, J. 2007. Introduction to coastal processes and geomorphology. Routledge.

Mulukutla, G. K., Huff, L. C., Melton, J. S., Baldwin, K. C., and Mayer, L. A. 2011. Sediment identification using free fall penetrometer acceleration-time histories. Marine Geophysical Research 32(3), pp. 397-411.

Murton, J. B. 2001. Thermokarst sediments and sedimentary structures, Tuktoyaktuk Coastlands, western Arctic Canada. Global and Planetary Change 28(1), pp. 175-192.

Obu, J., Lantuit, H., Myers-Smith, I., Heim, B., Wolter, J. and Fritz, M. 2015. Effect of Terrain Characteristics on Soil Organic Carbon and Total Nitrogen Stocks in Soils of Herschel Island, Western Canadian Arctic. Permafrost and Periglacial Processes, doi: 10.1002/ppp.1881.

O’Loughlin, C. D., Gaudin, C., Morton, J. P. and White, D. J. 2014. MEMS accelerometers for measuring dynamic penetration events in geotechnical centrifuge tests. Int. J. Phys. Modelling Geotech. 14(2), pp. 31-39.

Overpeck, J., Hughen, K., Hardy, D., Bradley, R., Case, R., Douglas, M., Finney, B., Gajewski, K., Jacoby, G., Jennings, A., Lamoureux, S., Lasca, A., MacDonals, G., Moore, J., Retelle, M., Smith, S., Wolfe, A., and Zielinski, G. 1997. Arctic environmental change of the last four centuries. Science 278(5341), pp. 1251-1256.

Paine, J. G., Andrews, J. R., Saylam, K., and Tremblay, T. A. 2015. Airborne LiDAR-Based Wetland and Permafrost-Feature Mapping on an Arctic Coastal Plain, North Slope, Alaska. In Remote Sensing of Wetlands: Applications and Advances, pp. 413-433.

Pelletier, B. R. 1987. Marine Science Atlas of the Beaufort Sea: Geology and Geophysics. Ottawa, Canada: Energy, Mines and Resources Canada: Canadian Government Publishing Centre. 
Peuchen, J. 2014. Accuracy of CPT. In: $3^{\text {rd }}$ International Symposium on Cone Penetration Testing, May 12-14, 2014, Las Vegas, Nevada, KN-2.

Ping, C. L., Jastrow, J. D., Jorgenson, M. T., Michaelson, G. J., and Shur, Y. L. 2015. Permafrost soils and carbon cycling. Soil 1(1), pp. 147-171.

Potyondy, J. G. 1961. Skin friction between various soils and construction materials. Geotechnique, 11(4), pp. 339-353.

Qi, J., Ma, W., and Song, C. 2008. Influence of freeze-thaw on engineering properties of a silty soil. Cold regions science and technology 53(3), pp. 397-404.

Radosavljevic, B., Lantuit, H., Pollard, W., Overduin, P., Couture, N., Sachs, T., Helm, V. and M. Fritz 2015. Erosion and Flooding-Threats to Coastal Infrastructure in the Arctic: A Case Study from Herschel Island, Yukon Territory, Canada. Estuaries and Coasts, pp. 1-16, doi:10.1007/s12237-015-0046-0.

Radosavljevic, B., Lantuit, H., Plessen, B., and C. Knoblauch 2016. Granulometry and Bulk Geochemistry of Nearshore Sediments, Herschel Island, Yukon Territory, Canada. Alfred Wegener Institute - Research Unit Potsdam, doi:10.1594/PANGAEA.859116

Randolph, M., and Gourvenec, S. 2011. Offshore geotechnical engineering. Spon Press, Abingdon, Oxon.

Reimnitz, E., Kempema, E. W., and Barnes, P. W. 1987. Anchor ice, seabed freezing, and sediment dynamics in shallow Arctic seas. Journal of Geophysical Research: Oceans (1978-2012) 92(C13), pp. 14671-14678.

Romanovsky, V.E., Smith, S.L. and Christiansen, H.H. 2010. Permafrost thermal state in the polar Northern Hemisphere during the international polar year 2007-2009: a synthesis. Permafrost and Periglacial Processes 21(2), pp.106-116.

Scott, R.F. 1970. In-place ocean soil strength by accelerometer. Journal of Soil Mechanics and Foundations Div 96(SM1), pp. 199-211. 
Seifert, A., Stegmann, S., Mörz, T., Lange, M., Wever, T., and Kopf, A. 2008. In situ porepressure evolution during dynamic CPT measurements in soft sediments of the western Baltic Sea. Geo-Marine Letters 28(4), pp. 213-227.

Stark, N., and Wever, T. F. 2009. Unraveling subtle details of expendable bottom penetrometer (XBP) deceleration profiles. Geo-Marine Letters 29(1), pp. 39-45.

Stark, N., and Kopf, A. 2011. Detection and quantification of sediment remobilization processes using a dynamic penetrometer. In OCEANS 2011, pp. 1-9.

Stark, N., Hanff, H., Svenson, C., Ernstsen, V. B., Lefebvre, A., Winter, C., and Kopf, A. 2011. Coupled penetrometer, MBES and ADCP assessments of tidal variations in surface sediment layer characteristics along active subaqueous dunes, Danish Wadden Sea. Geo-Marine Letters 31(4), pp. 249-258.

Stark, N., Teear, G, Flaim, B.K., and Kopf, A. 2011. High resolution fluid mud and soft mud layer quantification in ports using a dynamic penetrometer. In the Proceedings of the Coastal Sediments 2011, pp. 2424-2437.

Stark, N., Coco, G., Bryan, K. R., and Kopf, A. 2012. In-situ geotechnical characterization of mixed-grain-size bedforms using a dynamic penetrometer. Journal of Sedimentary Research 82(7), pp. 540-544.

Stark, N., Wilkens, R., Ernstsen, V. B., Lambers-Huesmann, M., Stegmann, S., and Kopf, A. 2012. Geotechnical properties of sandy seafloors and the consequences for dynamic penetrometer interpretations: quartz sand versus carbonate sand. Geotechnical and Geological Engineering 30(1), pp. 1-14.

Stark, N., Hay, A. E., Trowse, G., and Kopf, A. 2013. Geotechnical investigation of Grand Passage, Nova Scotia, with regard to sediment mobility and the installation of tidal energy converters. In Proceedings of the European Wave and Tidal Energy Conference Series, Aaalborg, Denmark, 2-5 September 2013. 
Stark, N., Staelens, P., Hay, A.E., Hatcher, B., and Kopf, A. 2014. Geotechnical investigation of coastal areas of difficult access using portable free fall penetrometers. In Proceedings of the CPT'14, Las Vegas, May 12-14, 2014.

Stark, N., Quinn, B., Lantuit, H., and Manson, G. 2015. Geotechnical investigation of coastal sediments at the Arctic permafrost edge: Results from an expedition to Herschel Island. In Proceedings of the Coastal Sediments 2015, World Scientific 2015.

Stark, N., Quinn, B., Ziotopoulou, K., and Lantuit, H. 2015. Geotechnical Investigation of Pore Pressure Behavior of Muddy Seafloor Sediments in an Arctic Permafrost Environment. In ASME 2015 34th International Conference on Ocean, Offshore and Arctic Engineering, pp. V001T10A017-V001T10A017.

Stephan, S., Kaul, N., and Villinger, H. 2015. Validation of impact penetrometer data by cone penetration testing and shallow seismic data within the regional geology of the Southern North Sea. Geo-Marine Letters 35(3), 203-219.

Stevens, C.W., Moorman, B.J., Solomon, S.M. and Hugenholtz, C.H. 2009. Mapping subsurface conditions within the near-shore zone of an Arctic delta using ground penetrating radar. Cold regions science and technology 56(1), pp.30-38.

Stevens, C.W., Moorman, B.J. and Solomon, S.M. 2010. Modeling ground thermal conditions and the limit of permafrost within the nearshore zone of the Mackenzie Delta, Canada. Journal of Geophysical Research: Earth Surface, 115(F4).

Stoll, R. D., and Akal, T. 1999. XBP- Tool for Rapid Assessment of Seabed Sediment Properties. Sea technology 40(2), pp. 47-52.

Stoll, R. D., Sun, Y. F., and Bitte, I. 2007. Seafloor properties from penetrometer tests. IEEE Journal of Oceanic Engineering 32(1), pp. 57-63.

Terzaghi, K. 1943. Theoretical soil mechanics. Wiley. 
Vaughan, D.G., J.C. Comiso, I. Allison, J. Carrasco, G. Kaser, R. Kwok, P. Mote, T. Murray, F. Paul, J. Ren, E. Rignot, O. Solomina, K. Steffen and T. Zhang 2013. Observations: Cryosphere. In: Climate Change 2013: The Physical Science Basis. Contribution of Working Group I to the Fifth Assessment Report of the Intergovernmental Panel on Climate Change [Stocker, T.F., D. Qin, G.-K. Plattner, M. Tignor, S.K. Allen, J. Boschung, A. Nauels, Y. Xia, V. Bex and P.M. Midgley (eds.)]. Cambridge University Press, Cambridge, United Kingdom and New York, NY, USA.

White, D. J., Gaudin, C., Boylan, N., and Zhou, H. 2010. Interpretation of T-bar penetrometer tests at shallow embedment and in very soft soils. Canadian Geotechnical Journal, 47(2), 218-229.

Wiemer, G., Moernaut, J., Stark, N., Kempf, P., De Batist, M., Pino, M., Urrutia, R., Ladron de Guevara, B., Strasser, M., and Kopf, A. 2015. The role of sediment composition and behavior under dynamic loading conditions on slope failure initiation: a study of a subaqueous landslide in earthquake-prone South-Central Chile. International Journal of Earth Sciences 104(5), pp. 1439-1457. 


\section{Figure captions}

Fig. 1 Location of the study area in the Canadian Beaufort Sea (A), the regional setting (B), and a map of the survey area showing the BlueDrop deployment locations (blue triangles), sediment grab samples (black dots), stabilized retrogressive thaw slumps (green) and active retrogressive thaw slumps (blue). The wind rose (D) shows the direction and speed frequency observed at the weather station on Simpson Point, Herschel Island, from 2009 to 2012 (Environment Canada, http://climate.weather.gc.ca/).

Fig. 2 The BlueDrop penetrometer before deployment during the YUKON14 field expedition to Herschel Island.

Fig. 3 BlueDrop measurements of two independent MEMS accelerometers of different range and accuracy, and pressure (for scale divided by 10) recording from WP 802. At this location the following challenges were encountered regarding identification of the point of sediment contact: wave action created noise in the deceleration record until the penetrometer touches the seabed $(\leq 0.1 \mathrm{~g})$, a terminal velocity was not achieved due to the shallow water depth $(<3 \mathrm{~m})$, and the seabed surface was comprised of very soft sediments (max. deceleration $<5.5 \mathrm{~g}$ ). Nevertheless, the point of contact with the seabed can be clearly identified in the deceleration record.

Fig. 4 BlueDrop penetrometer signatures from four exemplary locations within Pauline Cove (WP 793 and WP 802) and at Collinson Head (WP 787 and WP 774). Different shadings indicated different geotechnical responses and sediment resistances to the penetration of the probe. Four significantly different profiles were chosen to demonstrate the strong site- 
dependent differences. For the left panels of A) B), and C),D): The dashed line represents the penetration velocity, starting at impact velocity and decreasing to a halt. Measured deceleration is shown as the black solid line, representing the direct measurement without further processing. The deceleration starts at $0 \mathrm{~g}$ after correction of small offsets in response to the fact that terminal velocity was not reached in the case of very shallow water depths $(<$ $5 \mathrm{~m}$ ), or rope drag. The estimated equivalent of quasi-static bearing capacity $q s b c$ is indicated as a gray line with shading indicating uncertainty following the empirical strain rate correction factor. For the center panels in rows A) and B): The solid line represents the measured ambient pressure $u_{m}$, and the dashed line, the hydrostatic pressure $u_{0}$. In the right panels in rows A) and B): The solid line shows excess pore pressure $\Delta \boldsymbol{u}_{\boldsymbol{m}}=\boldsymbol{u}_{\boldsymbol{m}}-\boldsymbol{u}_{\mathbf{0}}$ and the dashed line gives an estimate of the pore pressure ratio $\boldsymbol{B}_{q}=\frac{\Delta \boldsymbol{u}_{m}}{\boldsymbol{q}_{\boldsymbol{t}}-\sigma_{v 0}}$ after Robertson (1990). The corrected tip resistance $q_{t}$ was estimated by using the quasi-static bearing capacity here. It was also assumed that the equilibrium pore pressure equals the hydrostatic pressure at the respective depth. Pore pressure assessments were not conducted for WP774 (C), because the penetration depth was not sufficient to embed the pore pressure transducer inlets, and thus, only hydrostatic pressure in the water column was displayed. It was also not presented for WP802 (D). Here, issues with the pore pressure measurements were noted (possibly related to air bubbles in the filter ring), and the results were excluded from further analysis.

Fig. 5 Quasi static bearing capacity (circles; for scaling of circle face color see right legend) superimposed on a natural neighbor interpolation of median grain size diameter classes (color shading with regard to sediment class) in Workboat Passage and SW Thetis Bay. 
Fig. $6 q s b c$ for different sediment types based on the interpolated sediment grain size map in Figure 5. Colors indicate the different survey zones.

Fig. 7 Overview map spatial distribution of the estimated maximum sediment resistance in the upper $1 \mathrm{~m}$ of the seabed surfaces around Collinson Head and MBES image near Simpson Point. Estimated maximum quasi-static bearing capacity is indicated by color of circles at the measurement sites. Red circles indicate deployment locations shown in Fig. 4.

Fig. 8 Impact velocity, penetration depth, measured deceleration, estimated maximum quasi-static bearing capacity and deepest top layer thickness along Pauline-Cross 1 and Thetis-Cross 4 with regard to water depth. The soil type based on the interpolated map and available samples shown in Fig. 4 is indicated in shading. Median grain size for the site with an available sediment sample is given. A mismatch between the soil type transitions and the penetrometer results can likely be related here to changes in fines content with regard to the measurement at penetration depth and a seabed surface grab surface. Particularly, in the shallower area, coarser silt at the surface is likely associated to the spit migration.

Fig. 9 Detailed map of maximum quasi-static bearing capacity in the Eastern Thetis Bay showing A) a natural neighbor interpolation of in relation to $d 50$ (A) and B) backscatter intensity. Shown as black circles are locations of sediment samples, while colored circles represent maximum quasi-static bearing capacity. (B).

Fig. 10 Measured deceleration-penetration depth profiles along Collinson 1 and 7 (Fig. 7). 
Fig. 11 Estimates of maximum quasi-static bearing capacity determined from the penetrometer versus median grain size determined from grab samples. The one muddy gravel sample and one hard impact into muddy sediments were excluded. Right) Zoom into muddy sediments. The mud locations with high $q s b c$ (light green shade) are all associated to transition zones from sand to mud around the spit of Simpson Point, or at the transition to sands going West along the profile of Thetis Bay (at Thetis-Cross 2). Mud sites with $50 \mathrm{kPa}$ $<q s b c<85 \mathrm{kPa}$ (dark green shade) were associated to sand-mud transition zones at ThetisCross 2, 4 and Collison 7. The penetrometer profiles indicated in these cases, soft sediments on a harder layer. Locations from Workboat Passage were omitted here, to avoid impact of the hypothesized fine sediment migration on the results.

Fig. $12 q s b c$ in the upper $10 \mathrm{~cm}$ of the seabed surface versus gravel, sand and mud content, and median grain size $d_{50}$.

Fig. 13 Penetration depth versus median grain size.

Fig. 14 Deceleration, velocity and $q s b c$ profiles from site WP 808. 


\section{Tables}

Table 1: Description of sediment samples and associated penetrometer results. The sediment texture was derived after Folk (1954).

\begin{tabular}{|c|c|c|c|c|c|}
\hline Transect & $\begin{array}{ll} & \text { W } \\
\text { P } & \end{array}$ & $\begin{array}{l}d_{50} \\
(\mu \mathrm{m})\end{array}$ & $\begin{array}{l}\text { dec } \\
(g)\end{array}$ & $\begin{array}{l}q s b c \\
(\mathrm{kPa})\end{array}$ & texture \\
\hline $\begin{array}{ll} & \text { Pau-Cross } \\
1 & \end{array}$ & $\begin{array}{r}7 \\
99\end{array}$ & 45 & 7 & 22 & Mud \\
\hline $\begin{array}{ll} & \text { Pau-Cross } \\
3 & \end{array}$ & $\begin{array}{r}8 \\
07\end{array}$ & 73 & 38 & 112 & gm sand \\
\hline $\begin{array}{ll} & \text { Pau-Cross } \\
3 & \end{array}$ & $\begin{array}{r}8 \\
08\end{array}$ & 50 & 65 & 202 & gs mud \\
\hline $\begin{array}{ll} & \text { Pau-Cross } \\
3 & \end{array}$ & $\begin{array}{r}8 \\
09\end{array}$ & 50 & 54 & 159 & gs mud \\
\hline $\begin{array}{l}\text { Thetis- } \\
\text { Cross } 1\end{array}$ & $\begin{array}{r}7 \\
55\end{array}$ & 46 & 8 & 24 & g mud \\
\hline $\begin{array}{l}\text { Thetis- } \\
\text { Cross } 1\end{array}$ & $\begin{array}{r}8 \\
15\end{array}$ & 47 & 7 & 18 & Gmud \\
\hline $\begin{array}{l}\text { Thetis- } \\
\text { Cross } 2\end{array}$ & $\begin{array}{r}8 \\
25\end{array}$ & 45 & 22 & 69 & g mud \\
\hline $\begin{array}{l}\text { Thetis- } \\
\text { Cross } 2\end{array}$ & $\begin{array}{r}8 \\
24\end{array}$ & 45 & 40 & 124 & g mud \\
\hline Thetis- & 8 & 47 & 21 & 65 & gs mud \\
\hline
\end{tabular}




\begin{tabular}{|c|c|c|c|c|c|}
\hline Cross 2 & 23 & & & & \\
\hline $\begin{array}{l}\text { Thetis- } \\
\text { Cross } 2\end{array}$ & $\begin{array}{r}8 \\
22\end{array}$ & 49 & 64 & 186 & s mud \\
\hline $\begin{array}{l}\text { Thetis- } \\
\text { Cross } 2\end{array}$ & $\begin{array}{r} \\
\\
21\end{array}$ & 46 & 11 & 34 & mud \\
\hline $\begin{array}{l}\text { Thetis- } \\
\text { Cross } 2\end{array}$ & $\begin{array}{r}8 \\
19\end{array}$ & 46 & 7 & 25 & mud \\
\hline $\begin{array}{l}\text { Thetis- } \\
\text { Cross } 3\end{array}$ & $\begin{array}{r}\{ \\
829\}\end{array}$ & 82 & 13 & 39 & gm sand \\
\hline $\begin{array}{l}\text { Thetis- } \\
\text { Cross } 4\end{array}$ & $\begin{array}{r}\{ \\
736\}\end{array}$ & 159 & 62 & 255 & $\mathrm{~m}$ sand \\
\hline $\begin{array}{l}\text { Thetis- } \\
\text { Cross } 4\end{array}$ & $\begin{array}{r}8 \\
43\end{array}$ & 49 & 27 & 83 & $\mathrm{~g}$ mud \\
\hline $\begin{array}{l}\text { Thetis- } \\
\text { Cross } 4\end{array}$ & $\begin{array}{r} \\
\\
31\end{array}$ & 47 & 8 & 27 & $\mathrm{~g}$ mud \\
\hline $\begin{array}{l}\text { Thetis- } \\
\text { Cross } 5\end{array}$ & $\begin{array}{r}8 \\
36\end{array}$ & 81 & 99 & 300 & gm sand \\
\hline $\begin{array}{l}\text { Thetis- } \\
\text { Long } 1\end{array}$ & $\begin{array}{r}7 \\
42\end{array}$ & 47 & 62 & 110 & $\mathrm{~m}$ sand \\
\hline $\begin{array}{l}\text { Thetis- } \\
\text { Long } 1\end{array}$ & $\begin{array}{l}5 \\
5 \\
5\end{array}$ & 74 & 62 & 238 & $\mathrm{~m}$ sand \\
\hline $\begin{array}{l}\text { Thetis- } \\
\text { Long } 1\end{array}$ & $\begin{array}{ll} & 6 \\
0 & \end{array}$ & 81 & 50 & 165 & $\mathrm{~m}$ sand \\
\hline
\end{tabular}




\begin{tabular}{|c|c|c|c|c|c|}
\hline $\begin{array}{l}\text { Thetis- } \\
\text { Long } 2\end{array}$ & $\begin{array}{r}8 \\
26\end{array}$ & 44 & 250 & 1000 & $\mathrm{~g}$ mud \\
\hline $\begin{array}{l}\text { Thetis- } \\
\text { Long } 2\end{array}$ & $\begin{array}{ll} & 9 \\
2 & \end{array}$ & 106 & 85 & 260 & $\mathrm{~m}$ sand \\
\hline $\begin{array}{l}\text { Thetis- } \\
\text { Long } 2\end{array}$ & $\begin{array}{r}8 \\
7\end{array}$ & 86 & 89 & 287 & gm sand \\
\hline Coll 1 & $\begin{array}{r}7 \\
61\end{array}$ & 53 & 6 & 17 & gs mud \\
\hline Coll 1 & $\begin{array}{r}7 \\
62\end{array}$ & 46 & 6 & 18 & $\mathrm{~g}$ mud \\
\hline Coll 2 & $\begin{array}{r}7 \\
66\end{array}$ & 55 & 61 & 185 & gs mud \\
\hline Coll 2 & $\begin{array}{r}7 \\
65\end{array}$ & 60 & 38 & 115 & gs mud \\
\hline Coll 2 & $\begin{array}{r}7 \\
63\end{array}$ & 50 & 7 & 20 & gs mud \\
\hline Coll 3 & $\begin{array}{r}7 \\
67\end{array}$ & 173 & 80 & 309 & g sand \\
\hline Coll 3 & $\begin{array}{r}7 \\
68\end{array}$ & 75 & 57 & 165 & gm sand \\
\hline Coll 3 & $\begin{array}{r}7 \\
69\end{array}$ & 48 & 9 & 22 & gs mud \\
\hline Coll 4 & 7 & 133 & 80 & 247 & gm sand \\
\hline
\end{tabular}




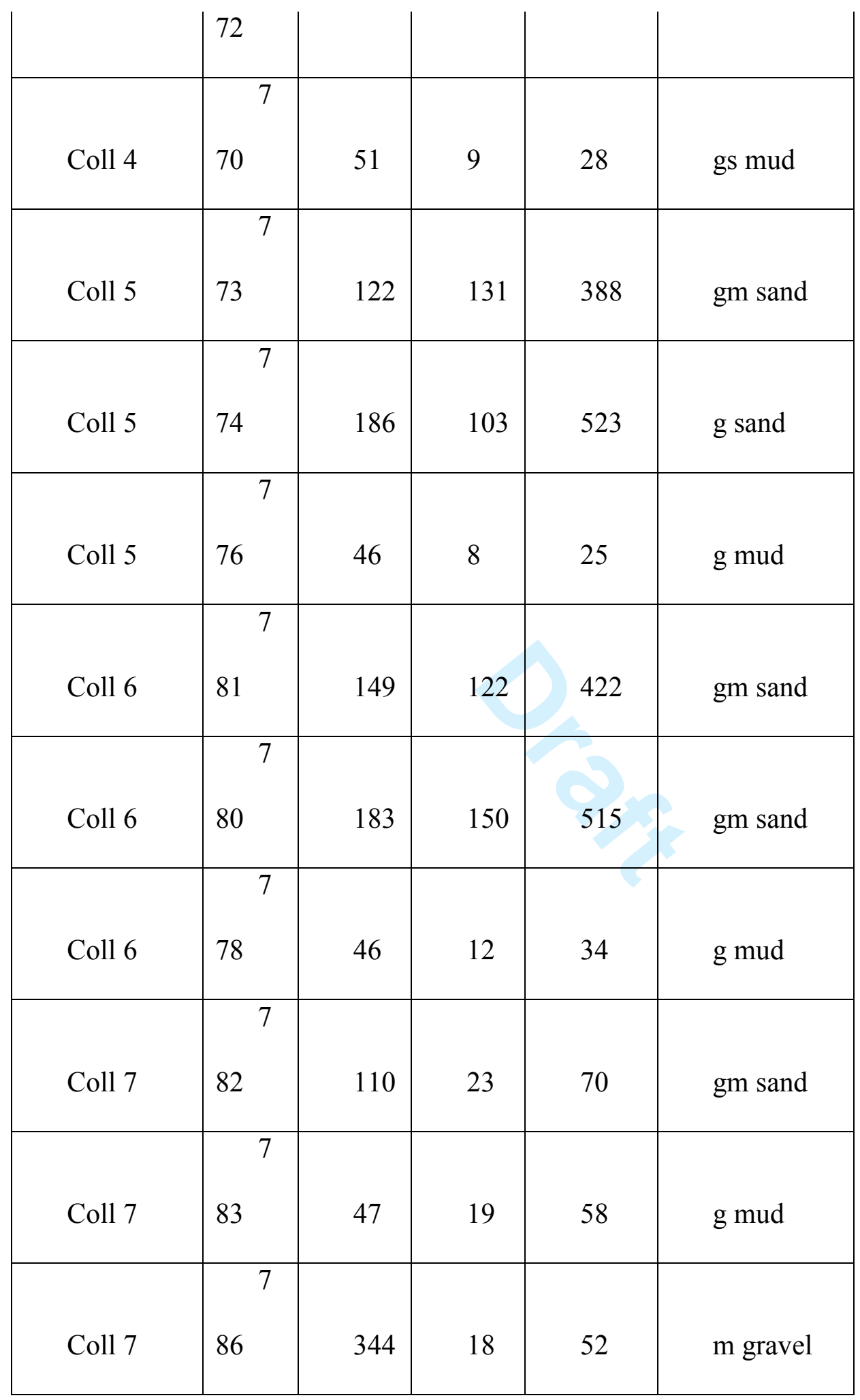




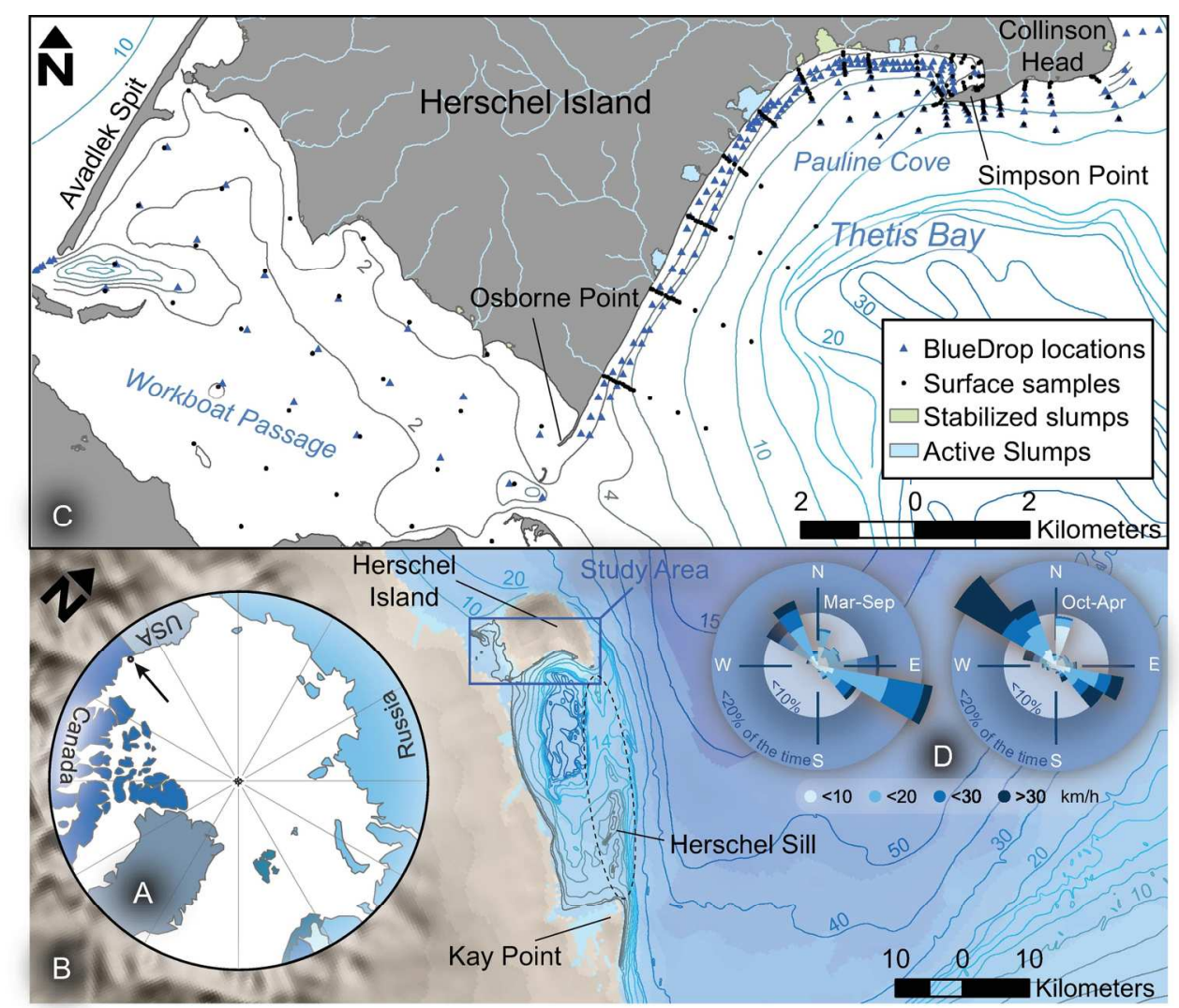

Fig. 1 Location of the study area in the Canadian Beaufort Sea (A), the regional setting (B), and a map of the survey area showing the BlueDrop deployment locations (blue triangles), sediment grab samples (black dots), stabilized retrogressive thaw slumps (green) and active retrogressive thaw slumps (blue). The wind rose (D) shows the direction and speed frequency observed at the weather station on Simpson Point, Herschel Island, from 2009 to 2012 (Environment Canada, http://climate.weather.gc.ca/).

Fig. 1

$162 \times 135 \mathrm{~mm}(300 \times 300 \mathrm{DPI})$ 


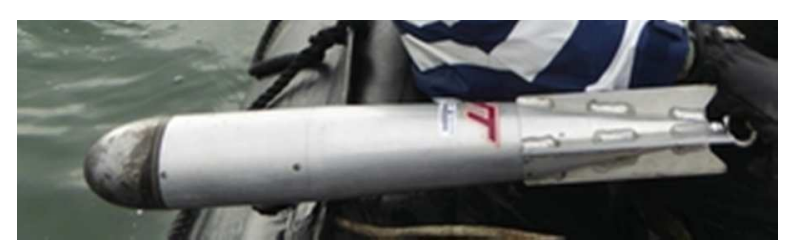

Fig. 2 The BlueDrop penetrometer before deployment during the YUKON14 field expedition to Herschel Island.

Fig. 2

$24 \times 7 \mathrm{~mm}(300 \times 300 \mathrm{DPI})$ 


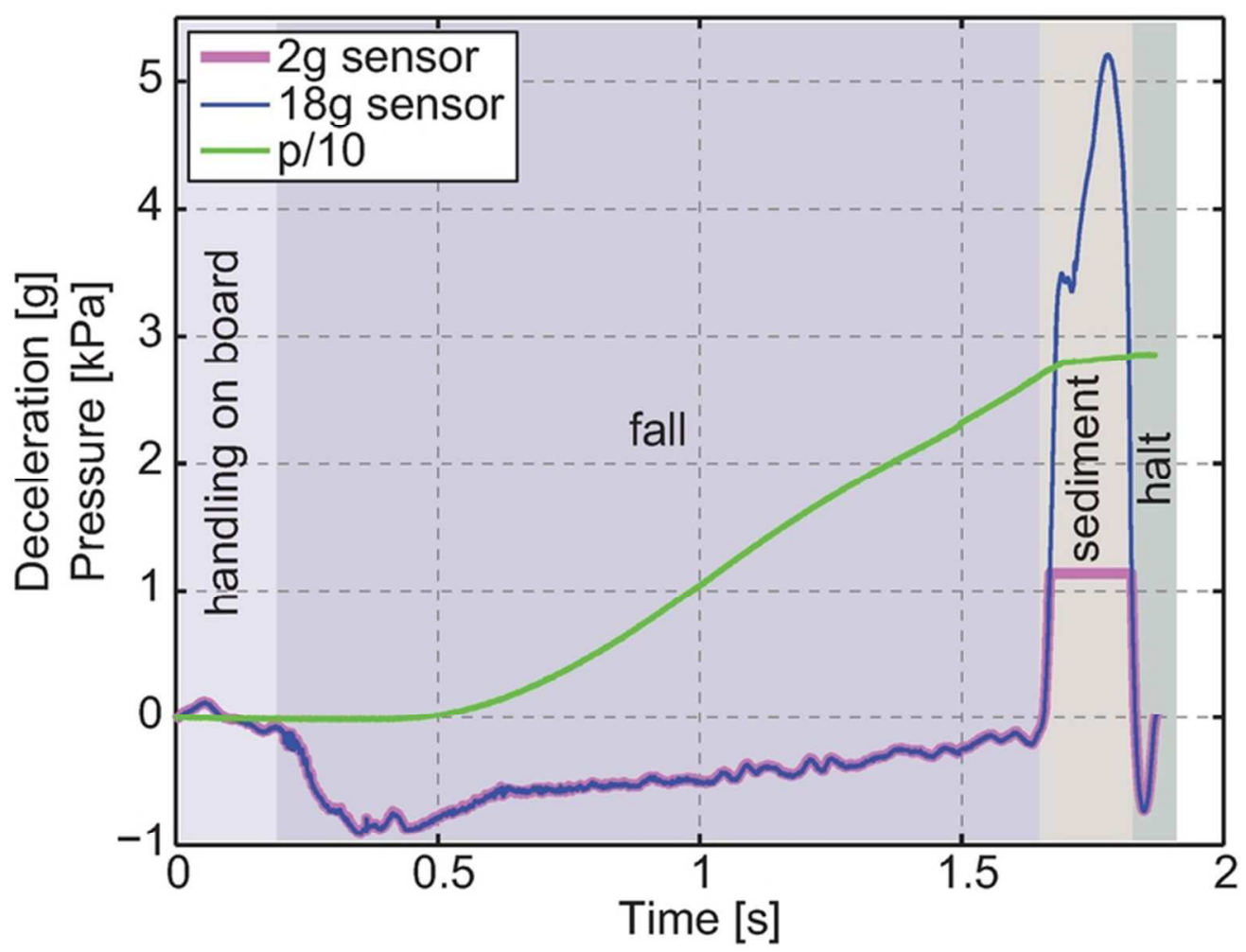

Fig. 3 BlueDrop measurements of two independent MEMS accelerometers of different range and accuracy, and pressure (for scale divided by 10) recording from WP 802. At this location the following challenges were encountered regarding identification of the point of sediment contact: wave action created noise in the deceleration record until the penetrometer touches the seabed $(\leq 0.1 \mathrm{~g})$, a terminal velocity was not achieved due to the shallow water depth $(<3 \mathrm{~m})$, and the seabed surface was comprised of very soft sediments (max. deceleration $<5.5 \mathrm{~g}$ ). Nevertheless, the point of contact with the seabed can be clearly identified in the deceleration record.

Fig. 3

$64 \times 49 \mathrm{~mm}(300 \times 300$ DPI $)$ 

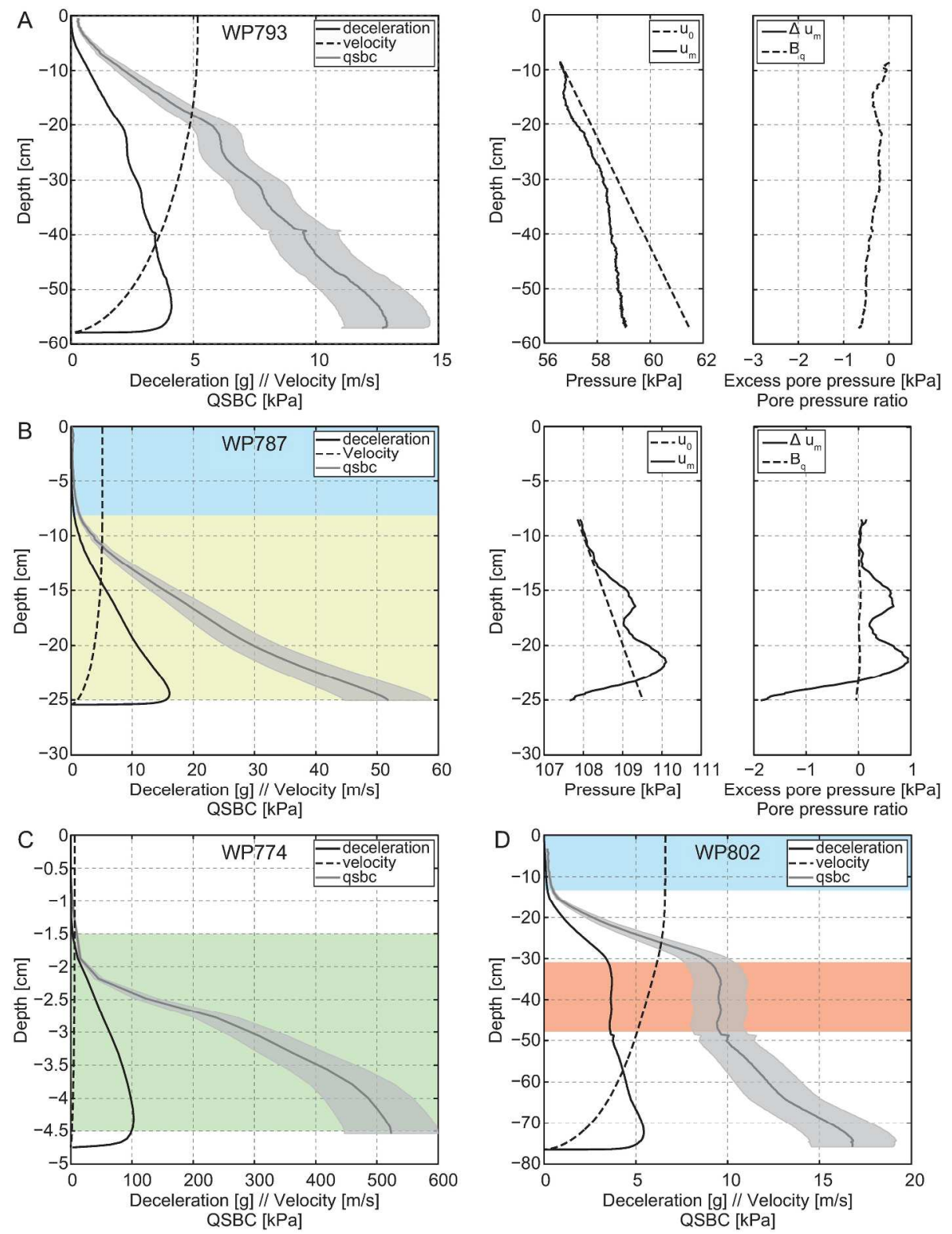

Fig. 4 BlueDrop penetrometer signatures from four exemplary locations within Pauline Cove (WP 793 and WP 802) and at Collinson Head (WP 787 and WP 774). Different shadings indicated different geotechnical responses and sediment resistances to the penetration of the probe. Four significantly different profiles were chosen to demonstrate the strong site-dependent differences. For the left panels of A) B), and C),D): The dashed line represents the penetration velocity, starting at impact velocity and decreasing to a halt. Measured deceleration is shown as the black solid line, representing the direct measurement without further processing. The deceleration starts at $0 \mathrm{~g}$ after correction of small offsets in response to the fact that terminal velocity was not reached in the case of very shallow water depths $(<5 \mathrm{~m})$, or rope drag. The estimated equivalent of quasi-static bearing capacity qsbc is indicated as a gray line with shading indicating uncertainty following the empirical strain rate correction factor. For the center panels in rows A) and B): The solid line represents the measured ambient pressure um, and the dashed line, the hydrostatic pressure u0. In the right panels in rows $A$ ) and $B$ ): The solid line shows excess pore pressure $\Delta \mathrm{u} \_m=u \_m-u \_0$ and the dashed line gives an estimate of the pore pressure ratio $B \_q=\left(\Delta u \_m\right) /\left(q \_t-\sigma \_v 0\right)$ after Robertson (1990). 
The corrected tip resistance qt was estimated by using the quasi-static bearing capacity here. It was also assumed that the equilibrium pore pressure equals the hydrostatic pressure at the respective depth. Pore pressure assessments were not conducted for WP774 (C), because the penetration depth was not sufficient to embed the pore pressure transducer inlets, and thus, only hydrostatic pressure in the water column was displayed. It was also not presented for WP802 (D). Here, issues with the pore pressure measurements were noted (possibly related to air bubbles in the filter ring), and the results were excluded from further analysis.

Fig. 4

$242 \times 319 m m(300 \times 300$ DPI $)$ 


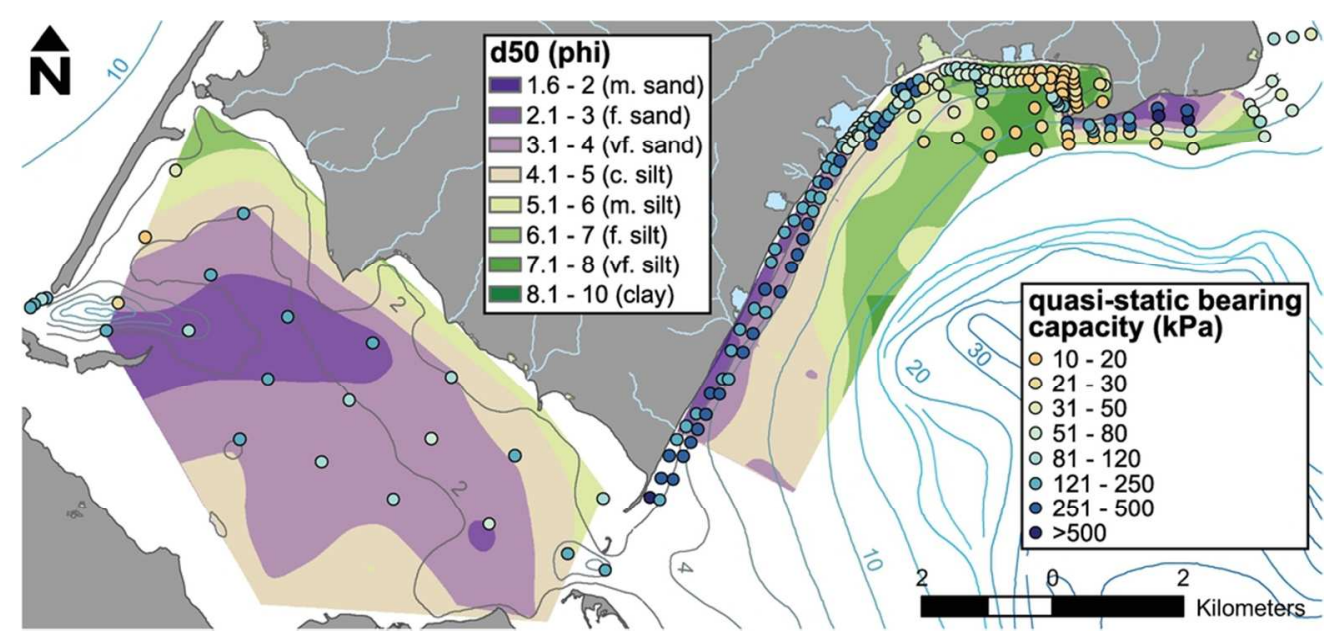

Fig. 5 Quasi static bearing capacity (circles; for scaling of circle face color see right legend) superimposed on a natural neighbor interpolation of median grain size diameter classes (color shading with regard to sediment class) in Workboat Passage and SW Thetis Bay.

Fig. 5

$88 \times 41 \mathrm{~mm}(300 \times 300$ DPI $)$ 


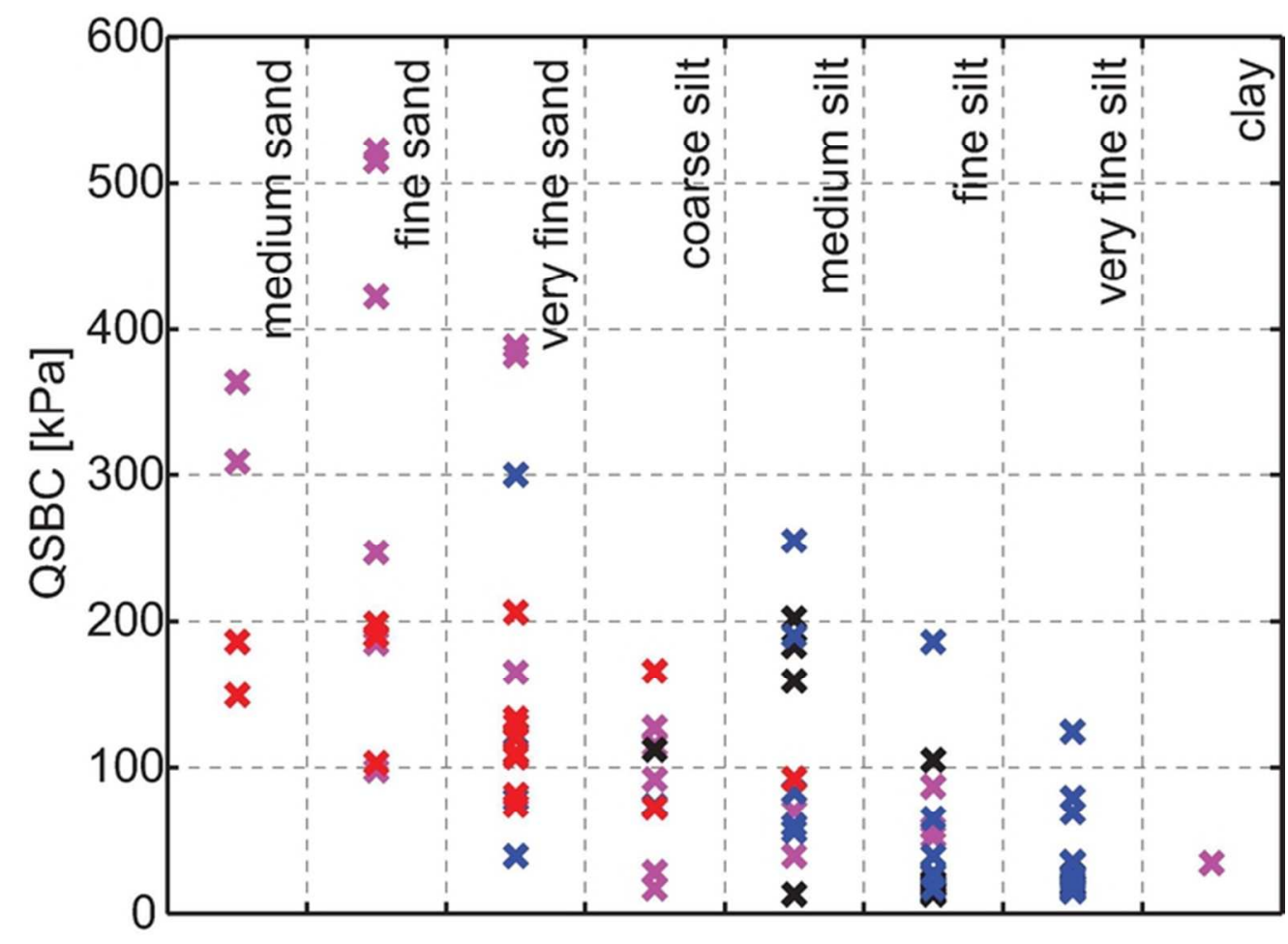

Fig. 6 qsbc for different sediment types based on the interpolated sediment grain size map in Figure 5. Colors indicate the different survey zones.

Fig. 6

$62 \times 46 \mathrm{~mm}(300 \times 300 \mathrm{DPI})$ 


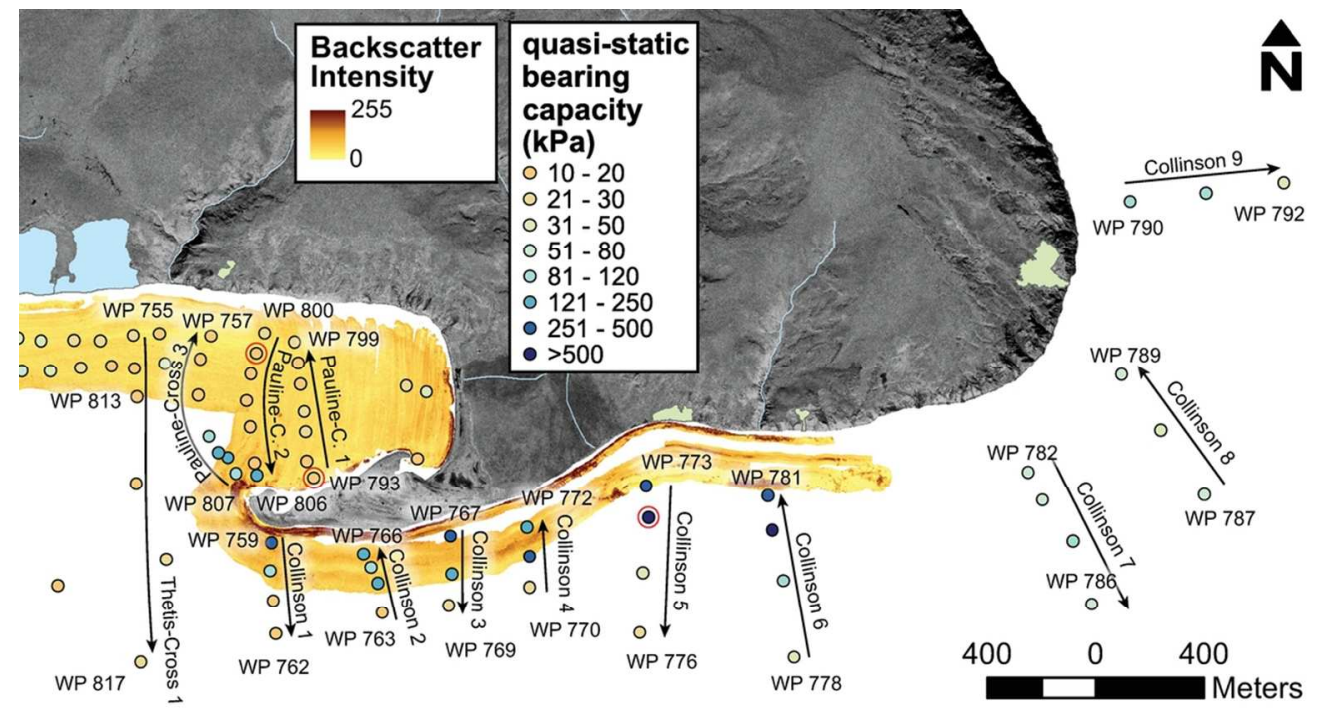

Fig. 7 Overview map spatial distribution of the estimated maximum sediment resistance in the upper $1 \mathrm{~m}$ of the seabed surfaces around Collinson Head and MBES image near Simpson Point. Estimated maximum quasi-static bearing capacity is indicated by color of circles at the measurement sites. Red circles indicate deployment locations shown in Fig. 4.

Fig. 7

$100 \times 55 \mathrm{~mm}(300 \times 300 \mathrm{DPI})$ 

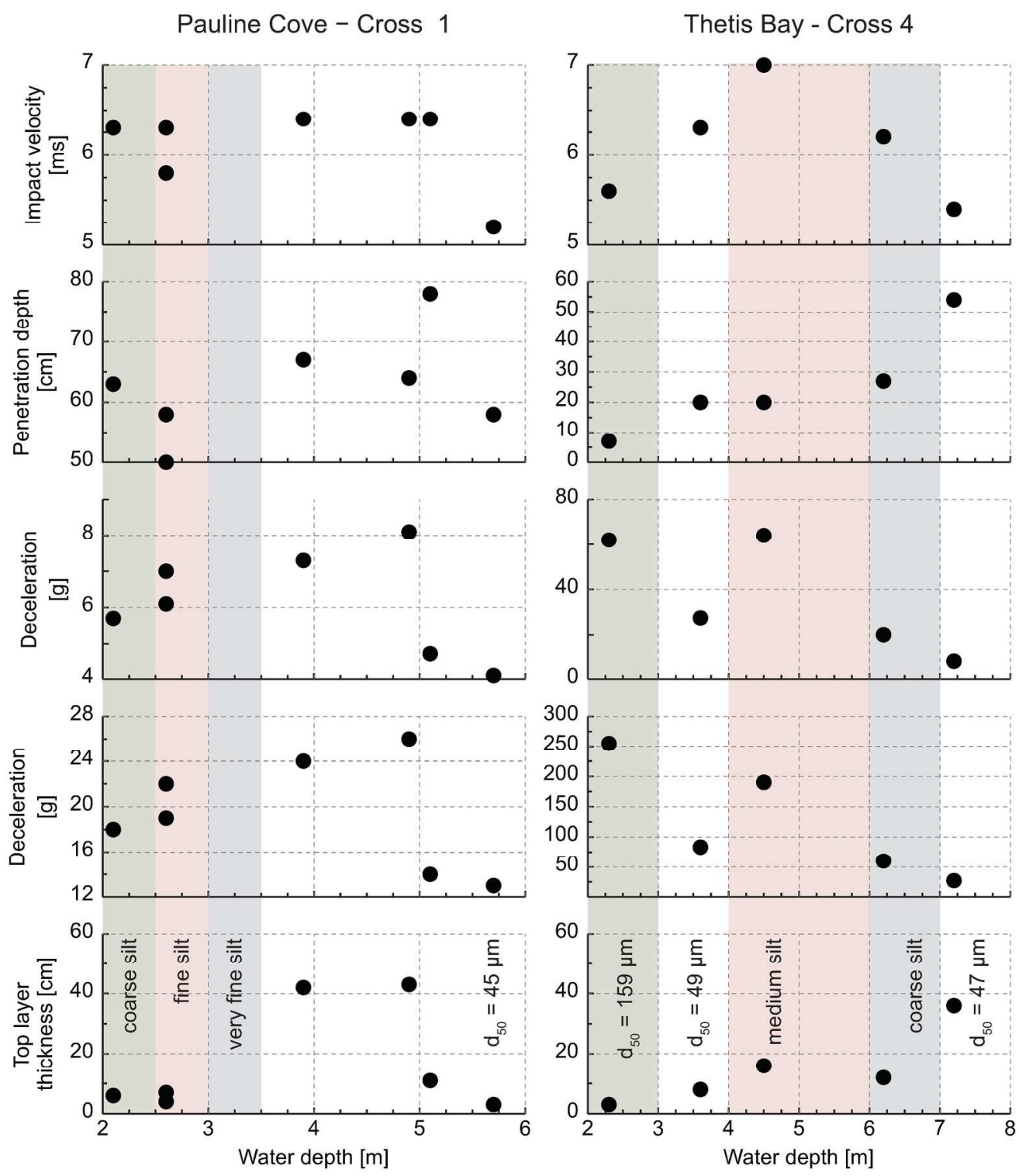

Fig. 8 Impact velocity, penetration depth, measured deceleration, estimated maximum quasi-static bearing capacity and deepest top layer thickness along Pauline-Cross 1 and Thetis-Cross 4 with regard to water depth. The soil type based on the interpolated map and available samples shown in Fig. 4 is indicated in shading. Median grain size for the site with an available sediment sample is given. A mismatch between the soil type transitions and the penetrometer results can likely be related here to changes in fines content with regard to the measurement at penetration depth and a seabed surface grab surface. Particularly, in the shallower area, coarser silt at the surface is likely associated to the spit migration.

Fig. 8

$193 \times 222 \mathrm{~mm}(300 \times 300$ DPI $)$ 


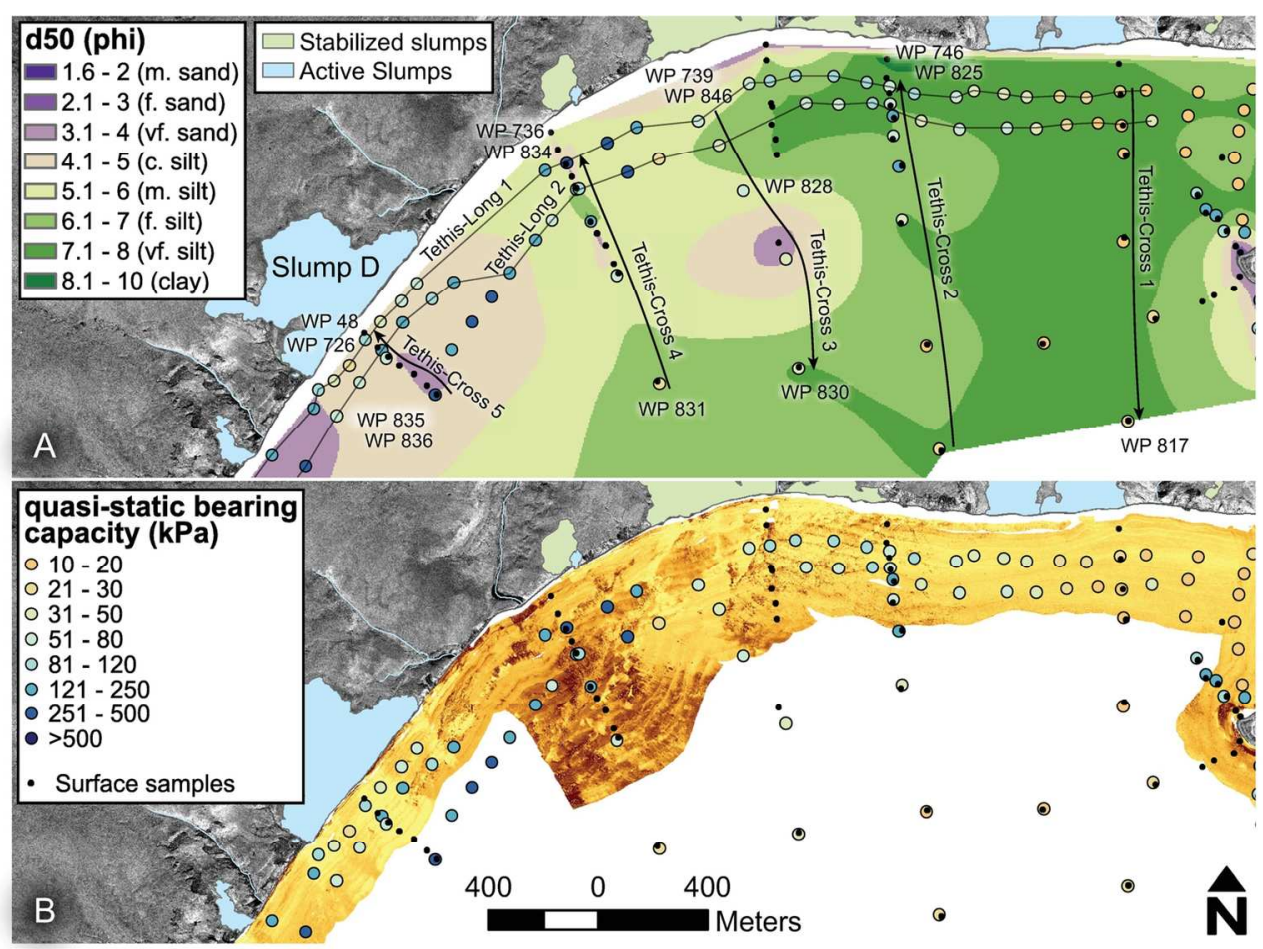

Fig. 9 Detailed map of maximum quasi-static bearing capacity in the Eastern Thetis Bay showing A) a natural neighbor interpolation of in relation to $d 50(A)$ and B) backscatter intensity. Shown as black circles are locations of sediment samples, while colored circles represent maximum quasi-static bearing capacity.

(B).

Fig. 9

$140 \times 104 \mathrm{~mm}(300 \times 300 \mathrm{DPI})$ 

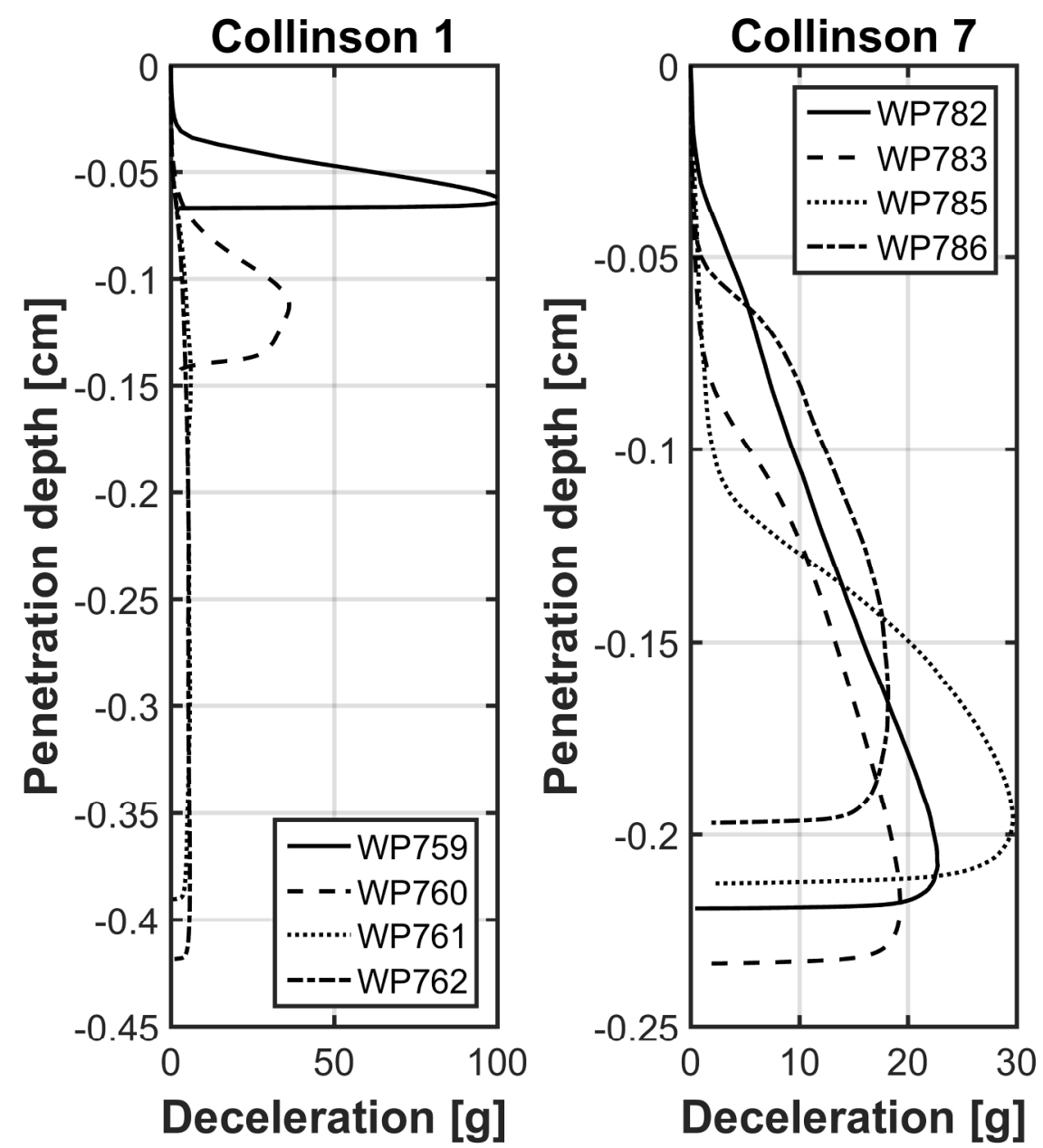

Fig. 10 Measured deceleration-penetration depth profiles along Collinson 1 and 7 (Fig. 7). Fig. 10 

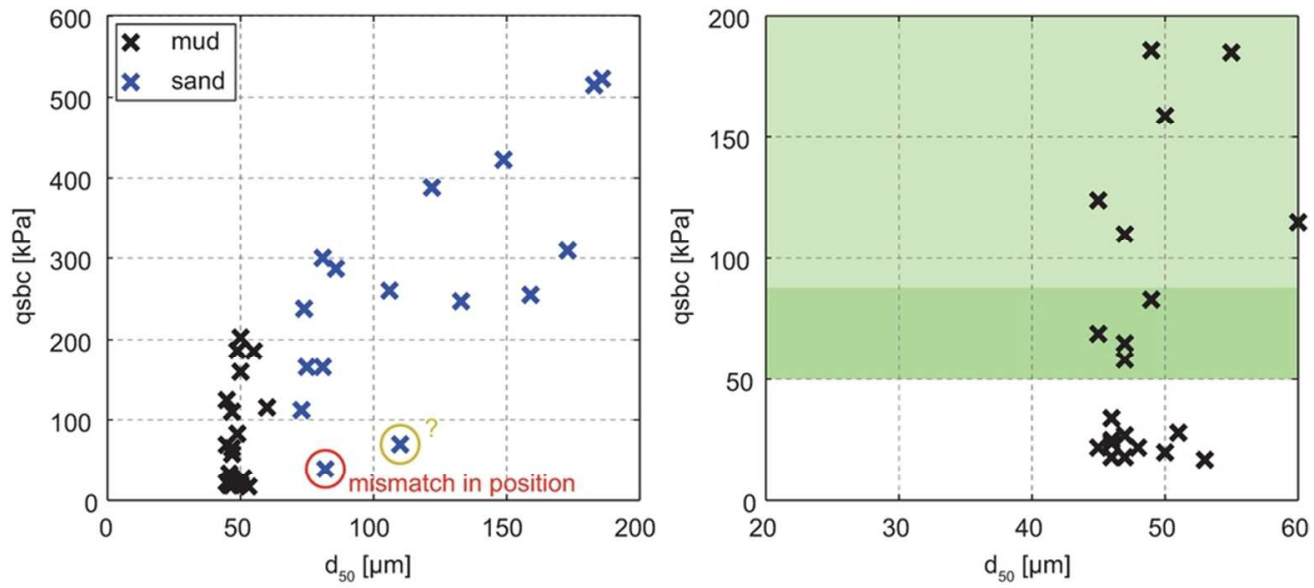

Fig. 11 Estimates of maximum quasi-static bearing capacity determined from the penetrometer versus median grain size determined from grab samples. The one muddy gravel sample and one hard impact into muddy sediments were excluded. Right) Zoom into muddy sediments. The mud locations with high qsbc (light green shade) are all associated to transition zones from sand to mud around the spit of Simpson Point, or at the transition to sands going West along the profile of Thetis Bay (at Thetis-Cross 2). Mud sites with 50 $\mathrm{kPa}<\mathrm{qsbc}<85 \mathrm{kPa}$ (dark green shade) were associated to sand-mud transition zones at Thetis-Cross 2, 4 and Collison 7. The penetrometer profiles indicated in these cases, soft sediments on a harder layer. Locations from Workboat Passage were omitted here, to avoid impact of the hypothesized fine sediment migration on the results.

Fig. 11

$81 \times 36 \mathrm{~mm}(300 \times 300 \mathrm{DPI})$ 

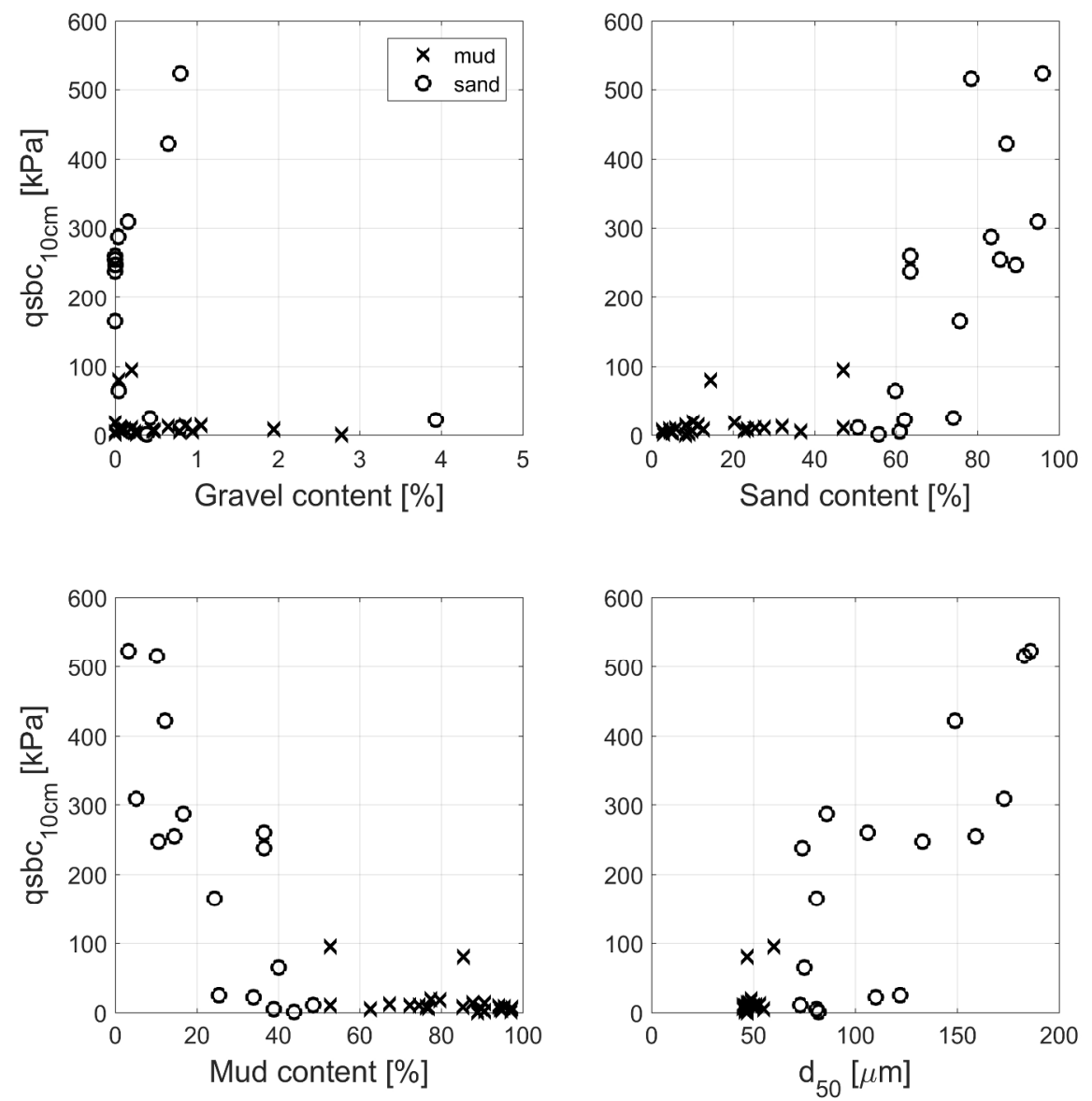

Fig. 12 qsbc in the upper $10 \mathrm{~cm}$ of the seabed surface versus gravel, sand and mud content, and median grain size $\mathrm{d} 50$. 


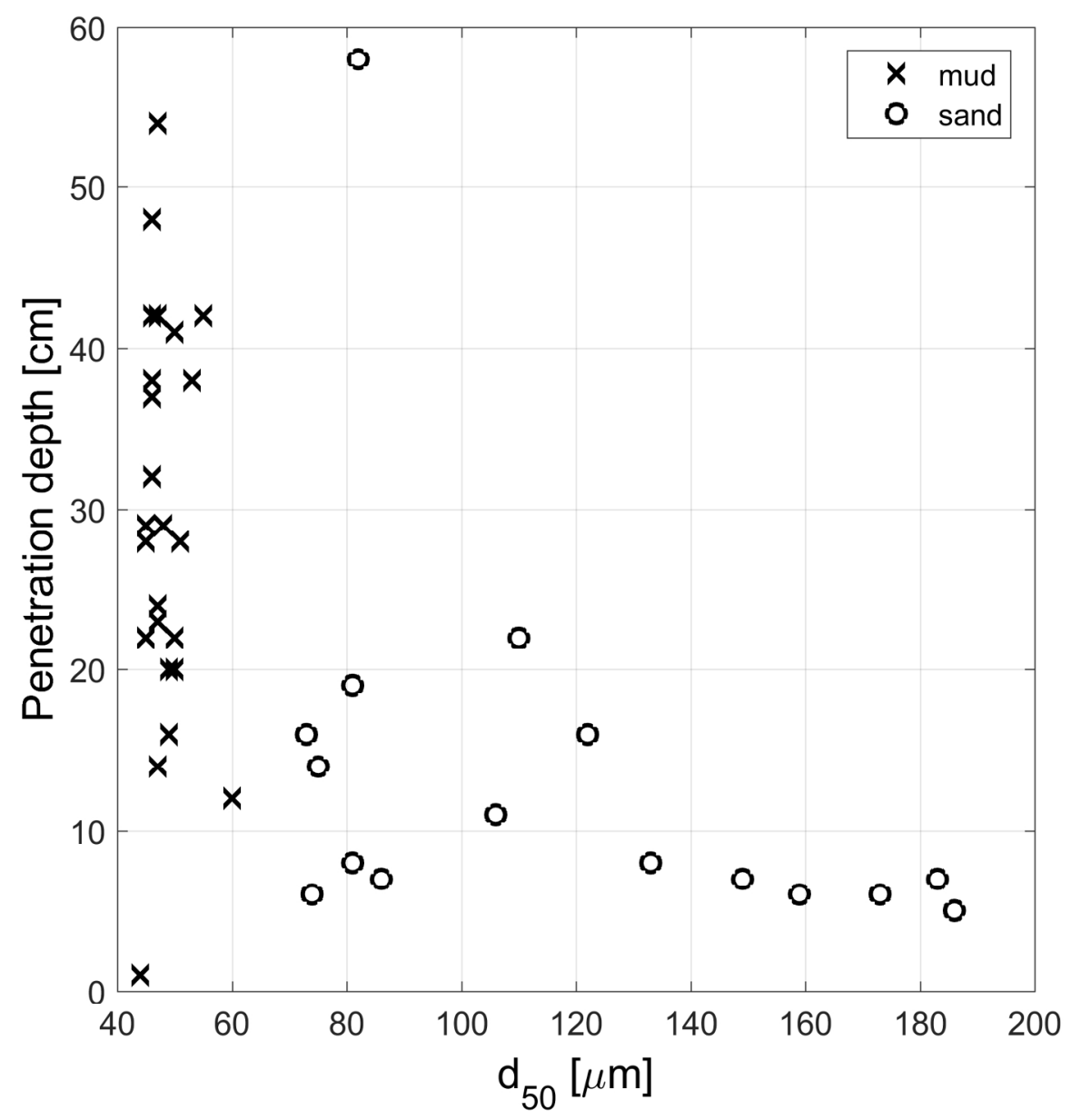

Fig. 13 Penetration depth versus median grain size. 


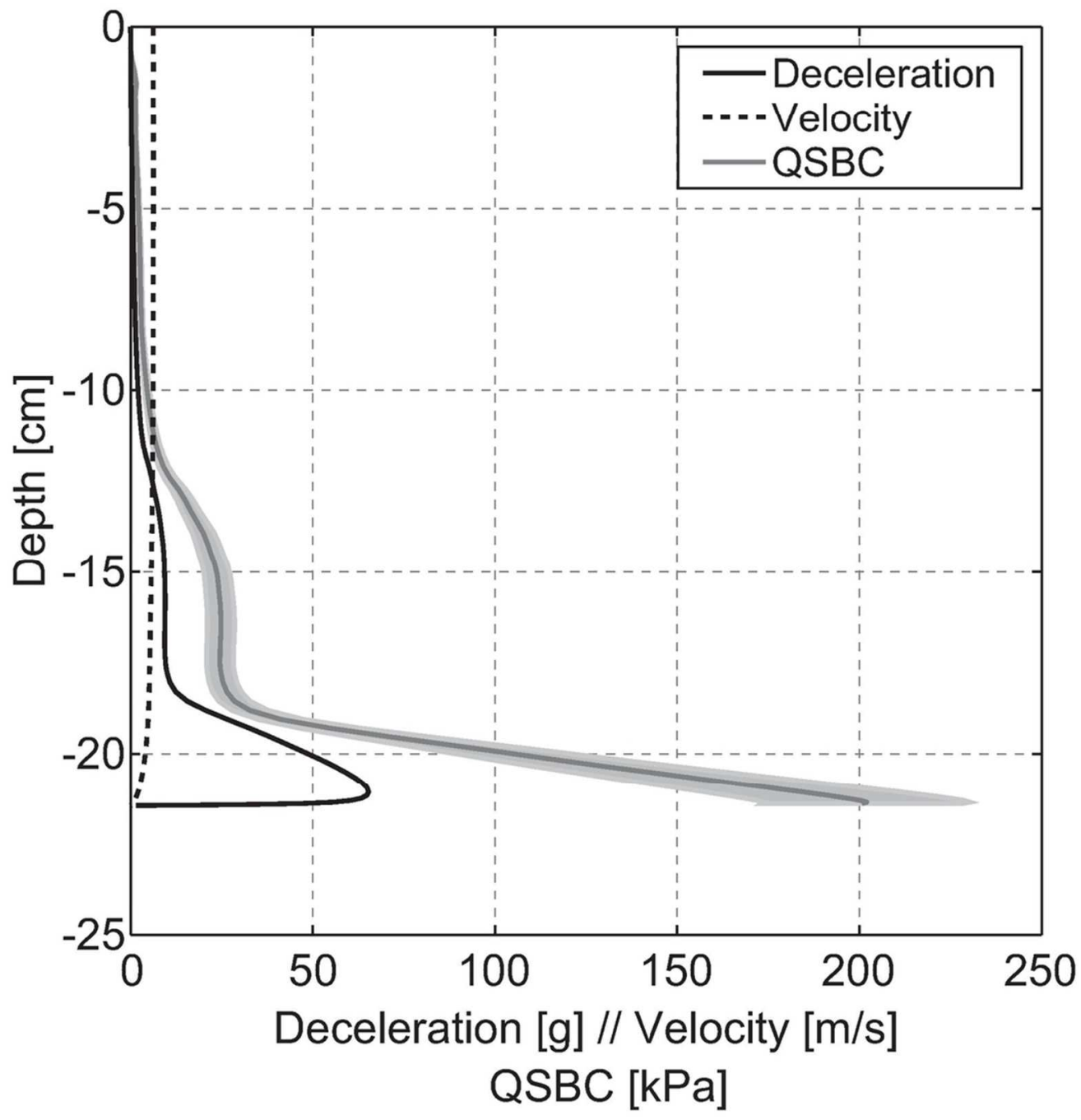

Fig. 14 Deceleration, velocity and qsbc profiles from site WP 808.

Fig. 14

$88 \times 91 \mathrm{~mm}(300 \times 300 \mathrm{DPI})$ 